University of Wollongong

Research Online

Faculty of Engineering and Information

Faculty of Engineering and Information

Sciences - Papers: Part B

Sciences

2020

\title{
Negative Sequence Voltage Compensating for Unbalanced Standalone Brushless Doubly-fed Induction Generator
}

Wei Xu

Huazhong University of Science and Technology

Omer Mohammed Elbabo Mohammed

Huazhong University of Science and Technology

Yi Liu

Huazhong University of Science and Technology, yiliu@uow.edu.au

Md Rabiul Islam

University of Wollongong, mrislam@uow.edu.au

Follow this and additional works at: https://ro.uow.edu.au/eispapers1

Part of the Engineering Commons, and the Science and Technology Studies Commons

Research Online is the open access institutional repository for the University of Wollongong. For further information contact the UOW Library: research-pubs@uow.edu.au 


\title{
Negative Sequence Voltage Compensating for Unbalanced Standalone Brushless Doubly-fed Induction Generator
}

\author{
Abstract \\ During the unbalance operation of a standalone brushless doubly-fed induction generator (BDFIG), the \\ negative sequence component causes significant unbalanced effect on the voltage and current of the \\ power winding (PW). In this paper, anew control strategy is proposed to minimize the voltage unbalance \\ effect of a standalone BDFIG under unbalanced loads. The proposed control strategy consists of two \\ parts. The first part represents the conventional direct voltage control (DVC) strategy to control the \\ frequency and magnitude of the positivesequence PW voltage. The second part is the proposed strategy \\ to minimize the negative sequence component in the output voltage of PW with a negative sequence \\ compensator in the machine side converter (MSC). The dual second-order generalized integrator (DSOGI) \\ is used to extract negative-sequence component of the PW voltage. Proportional integral controllers are \\ used to obtain reference of the control winding $(\mathrm{CW})$ current which compensate the negative sequence \\ component of the PW voltage. The proportional-integral-resonant (PIR) controller is applied to regulate \\ the $\mathrm{CW}$ current in positive reference frame. A prototype $30 \mathrm{kVA}$ BDFIG test platform is developed in the \\ laboratory to verify the proposed strategy.

\section{Keywords} \\ generator, induction, doubly-fed, brushless, standalone, unbalanced, compensating, negative, sequence, \\ voltage \\ Disciplines \\ Engineering | Science and Technology Studies

\section{Publication Details} \\ W. Xu, O. Elbabo. Mohammed, Y. Liu \& M. Islam, "Negative Sequence Voltage Compensating for \\ Unbalanced Standalone Brushless Doubly-fed Induction Generator," IEEE Transactions on Power \\ Electronics, vol. 35, (1) pp. 667-680, 2020.
}




\title{
Negative Sequence Voltage Compensating for Unbalanced Standalone Brushless Doubly-fed Induction Generator
}

\author{
Wei Xu, Senior Member, IEEE, Omer Mohammed Elbabo Mohammed, Yi Liu, Member, IEEE, \\ and Md Rabiul Islam, Senior Member, IEEE
}

\begin{abstract}
During the unbalance operation of a standalone brushless doubly-fed induction generator (BDFIG), the negative sequence component causes significant unbalanced effect on the voltage and current of the power winding (PW). In this paper, a new control strategy is proposed to minimize the voltage unbalance effect of a standalone BDFIG under unbalanced loads. The proposed control strategy consists of two parts. The first part represents the conventional direct voltage control (DVC) strategy to control the frequency and magnitude of the positive sequence PW voltage. The second part is the proposed strategy to minimize the negative sequence component in the output voltage of $P W$ with a negative sequence compensator in the machine side converter (MSC). The dual second-order generalized integrator (DSOGI) is used to extract negative-sequence component of the PW voltage. Proportional integral controllers are used to obtain reference of the control winding $(\mathrm{CW})$ current which compensate the negative sequence component of the $P W$ voltage. The proportional-integral-resonant (PIR) controller is applied to regulate the $\mathrm{CW}$ current in positive reference frame. A prototype $30 \mathrm{kVA}$ BDFIG test platform is developed in the laboratory to verify the proposed strategy.
\end{abstract}

Index Terms- Brushless doubly-fed induction generator (BDFIG), standalone power generation system, negativesequence component, unbalanced load.

\section{INTRODUCTION}

The features such as robustness and reliability without brushes and slip rings have been making brushless double fed induction generator (BDFIG) a promising technology for emerging standalone applications, e.g. ship shaft power generation and offshore wind power generation [1], [2]. The BDFIG consists of three main parts: the stator power winding $(\mathrm{PW})$, the stator control winding $(\mathrm{CW})$ and the distinctive

Wei Xu, Omer Mohammed Elbabo Mohammed and Yi Liu (Corresponding Author) are with the State Key Laboratory of Advanced Electromagnetic Engineering and Technology, School of Electrical and Electronic Engineering, Huazhong University of Science and Technology, Wuhan, 430074, China. (Emails: weixu@hust.edu.cn; babo271@yahoo.com; liuyi82@hust.edu.cn)

Omer Mohammed Elbabo Mohammed is also with the Department of Electrical Engineering, Faculty of Engineering, University of Sinnar, Sinnar, Sudan.

Md Rabiul Islam is with the School of Electrical, Computer and Telecommunications Engineering. University of Wollongong, New South Wales 2521, Australia. (E-mail: mrislam@uow.edu.au).

This work has been partly supported by the National Natural Science Foundation of China (NSFC 51707079, 51877093 and 51807075) and National Key Research and Development Program of China (Project ID: 2018YFE0100200). rotor [3], [4]. Figure 1 shows the basic block diagram of a BDFIG-based standalone power generation system.

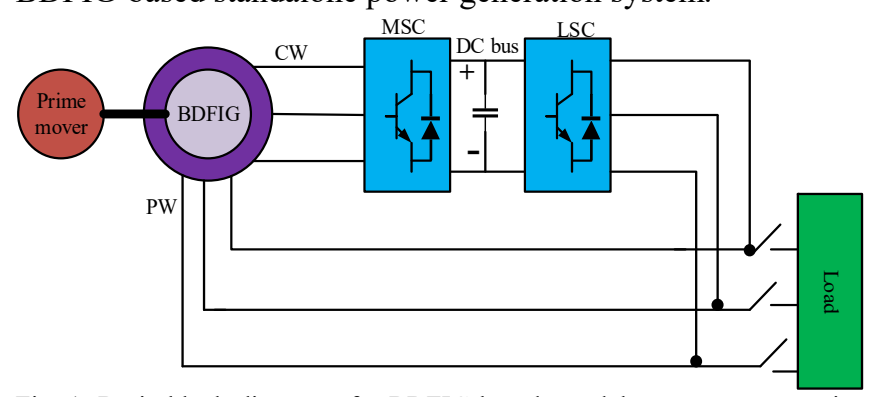

Fig. 1. Basic block diagram of a BDFIG-based standalone power generation system.

In the grid-connected mode, the main purposes of control strategies are to preserve the generator active and reactive power and for the treatment of undesirable conditions in the system [5]-[10]. The stator-flux-oriented vector control (VC) method has been presented in [5], where the dynamic control of reactive power for the BDFIG has been developed with a VC scheme. In [6], [7], a practical control method of BDFIG has been designed to ride through symmetrical and asymmetrical low-voltage faults (LVRT) without utilizing extra protective hardware.

Another control method has been adopted to enhance control of active and reactive power under transient conditions [8]. Direct power control (DPC) technique is robust and has fast response capability with transient situations. Nevertheless, it suffers from current distortions and ripples in the active and reactive power, which decreases the quality of the output power. To overcome the drawbacks of DPC, super twisting sliding mode (SSM) can be integrated with DPC, as the SSM is an effective control strategy for nonlinear systems with parameter variations and big disturbance. A SSM direct power control (SSM-DPC) strategy has been presented in [8].

The negative sequence component during unbalanced condition may produce a large number of problems in a BDFIG, such as substantial oscillations at twice PW frequency in the output voltage and torque. In [9], authors have presented a VC method for BDFIG under the unbalanced grid mode, where a dual synchronous frame structure was applied to control the forward and backward components of the positive and negative frames. The unbalanced effect of PW voltage can be mitigated by compensating the negative component in the positive frame. 
In [10], an improved VC (proportional integral resonant controller in single synchronous frame) for BDFIG under unbalanced grid conditions has been presented, which eliminates the decomposition of negative sequence voltage and current.

In a standalone mode, the frequency and amplitude of the PW voltage must be stable when rotor speed or load varies [11]-[17]. A scalar control method based on fuzzy proportional-integral-derivative controller (PID) has been presented in [11], which may decreases the cost of control system. In [12] and [13], a control scheme for standalone ship shaft generator systems has been presented, which consist of three different controllers to regulate current of $\mathrm{CW}$, amplitude of PW voltage, and frequency of PW. In addition, numerical frequency domain controller for BDFIG has been presented in [14], to avert the intricate deviations to acquire more exact design results. In [15], authors have addressed an undesirable transient operation when the load is unexpectedly disconnected or connected from the PW. To overcome this problem, a reactive current based high-voltage ride-through (HVRT) control method of the load-side converter (LSC) has been developed [15].

The effects of unbalanced load in a ship shaft power generation system have been presented in [16] and [17]. In [16], the control scheme composes of two parts, where the first part is the PW voltage controller used to maintain the constant frequency and magnitude of the PW voltage, and second part is the PW voltage compensator employed to compensate the unbalance effect in the PW voltage. The PW voltage compensator works separately from the first part and provides the additional three-phase $\mathrm{CW}$ voltage for compensating unbalanced $\mathrm{PW}$ voltage. As a result, the system takes a longer time to reach a steady state when compensating unbalanced load. And, this control scheme needs many filters and feedback quantities, which makes the system complex. In [17], an improved sensorless phase control method is adopted to minimize the unbalance loading effects. The main defect of this method is that an extra control loop (an adaptive compensator of phase error with a nonlinear operator) is employed to regulate the phase angle, which increases the probability of error occurs in the compensation process.

To address the previously mentioned problems under unbalanced loads in the standalone BDFIG, a new control strategy is proposed in this paper. The proposed strategy is composite of two parts: the first part is the conventional direct voltage control (DVC) strategy to control the frequency and magnitude of the positive sequence PW voltage, and the second part is the proposed compensator to minimize the negative sequence component of the PW voltage. The performance of the proposed strategy is verified by both the simulation and experimental results. The design methodology and simulation and experimental results are analyzed and presented in this paper. Although the propose strategy is similar to the other two typical strategies proposed in [16] and [17] in the two aspects of control targets and implementation principles, the three strategies differ in key measures of implementation, numbers of sampled feedback quantities, and numbers of P, PI and PIR controllers. The strategy proposed in this paper can be regarded as the simplest one among the three strategies due to the use of the fewest P, PI and PIR controllers. It is expected that the proposed strategy will be a promising technology for different standalone applications, such as in wind farms and ship shaft systems.

\section{CONFIGURATION AND GENERIC MATHEMATICAL MODEL OF BDFIG}

\section{A. Configuration of BDFIG}

The rotor speed of a BDFIG can be expressed as

$$
\omega_{r}=\left(\omega_{p}+\omega_{c}\right) /\left(p_{p}+p_{c}\right)
$$

where $p$ is the pole pair, and $\omega$ the angular speed. The subscript $p, c$, and $r$ indicate $\mathrm{PW}, \mathrm{CW}$, and rotor, respectively.

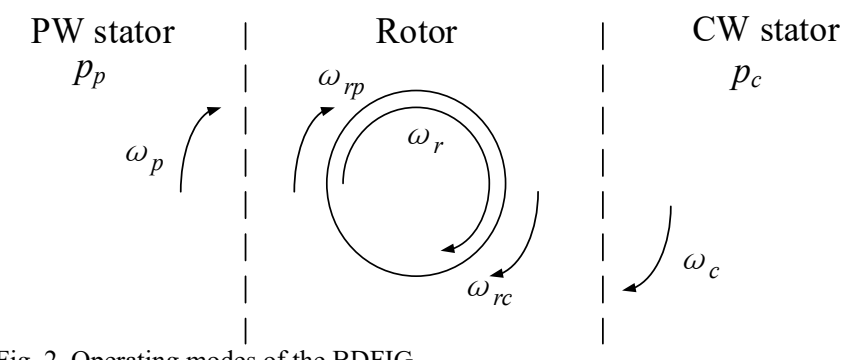

Fig. 2. Operating modes of the BDFIG.

From Fig. 2, $\omega_{r p}$ and $\omega_{r c}$ are defined as the slip frequencies of PW and CW, respectively. And then, the two parameters can be expressed as

$$
\begin{aligned}
& \omega_{r p}=\omega_{p}-p_{p} \omega_{r} \\
& \omega_{r c}=\omega_{c}-p_{c} \omega_{r} .
\end{aligned}
$$

When $\omega_{c}$ equal zero, the rotor will rotate under natural synchronous speed $\omega_{N}$, which can be expressed as

$$
\omega_{N}=\omega_{p} /\left(p_{p}+p_{c}\right) \text {. }
$$

When the rotor speed works above and below $\omega_{N}$, the speed of rotor called super-synchronous and sub-synchronous respectively. The value of $\omega_{c}$ should change directly when the $\omega_{r}$ varies, to maintain $\omega_{p}$ constant [13].

\section{B. Mathematical Model of BDFIG}

The mathematical model of a BDFIG can be expressed as [18]

$$
\begin{aligned}
& u_{p}=R_{p} i_{p}+s \varphi_{p}+j \omega_{p} \varphi_{p} \\
& u_{c}=R_{c} i_{c}+s \varphi_{c}-j \omega_{c} \varphi_{c} \\
& u_{r}=R_{r} i_{r}+s \varphi_{r}+j\left(\omega_{p}-P_{p} \omega_{r}\right) \varphi_{r} \\
& \varphi_{p}=L_{p} i_{p}+M_{p r} i_{r} \\
& \varphi_{c}=L_{c} i_{c}+M_{c r} i_{r} \\
& \varphi_{r}=L_{r} i_{r}+M_{p r} i_{p}+M_{c r} i_{c}
\end{aligned}
$$

where $u, i$ and $\varphi$ represent the voltage, current and flux vectors; $R, L$, and $M$ represent the resistance, self-inductance, and mutual inductance; $s$ indicates derivative term. 


\section{Performance ANALYsis of A BDFIG Under UNBALANCED LOADS}

When the load is unbalanced, the flux, current and voltage can be divided into the positive and negative components as like

$$
F^{+}=\underbrace{F_{+}^{+}}_{\text {postive component }}+\underbrace{F_{-}^{+}}_{\text {negative component }}=\underbrace{F_{+}^{+}}_{\text {postive component }}+\underbrace{F_{-}^{-} e^{-j 2 \omega_{p} t}}_{\text {negative component }}
$$

where $F$ represents the value of voltage, flux, and current; the subscripts "+" "-" indicate the positive and negative sequences and the superscripts "+" "-" indicate positive and negative reference frames.

According to (1), the frequencies of positive and negative components of $\mathrm{CW}$ and rotor quantities can be deduced from the corresponding voltages applied on $\mathrm{PW}$, which are listed in Table I.

TABLE I

FREQUENCIES IN STATOR AND ROTOR UNDER UNBALANCED LOAD

\begin{tabular}{|c|c|c|c|}
\hline & PW frequency & $\begin{array}{c}\text { Rotor } \\
\text { frequency }\end{array}$ & $\begin{array}{c}\text { CW } \\
\text { frequency }\end{array}$ \\
\hline $\begin{array}{c}\text { Positive } \\
\text { component }\end{array}$ & $\omega_{p}$ & $\omega_{p}-P_{p} \omega_{r}$ & $\omega_{c}$ \\
\hline $\begin{array}{c}\text { Negative } \\
\text { component }\end{array}$ & $-\omega_{p}$ & $-\omega_{p}-P_{p} \omega_{r}$ & $2 \omega_{p}+\omega_{c}$ \\
\hline
\end{tabular}

In Table I, $\omega_{c}$ can be derived from (1) and expressed as $\omega_{c}=\left(p_{p}+p_{c}\right) \omega_{r}-\omega_{p}$.

From Table I, it can be seen that the negative components of PW, CW and rotor quantities are all rotating at two times of PW fundamental frequency relative to the corresponding positive components of these quantities.

From (11), the voltage, current, and flux vectors of PW in the positive reference frame can be expressed as

$$
\left\{\begin{array}{l}
u_{p}^{+}=u_{P_{+}}^{+}+u_{p_{-}}^{-} e^{-j 2 \omega_{p} t} \\
i_{p}^{+}=i_{P+}^{+}+i_{p-}^{-} e^{-j 2 \omega_{p} t} \\
\varphi_{p}^{+}=\varphi_{P_{+}}^{+}+\varphi_{p-}^{-} e^{-j 2 \omega_{p} t}
\end{array}\right.
$$

By substituting (12) into (5) and (8), the PW positive and negative sequence components voltage equations in the corresponding reference frames can be derived as

$$
\begin{aligned}
& u_{p^{+}}^{+}=R_{p} i_{p^{+}}^{+}+s \varphi_{p_{+}^{+}}^{+}+j \omega_{p} \varphi_{p+}^{+} \\
& u_{p_{-}}^{-}=R_{p} i_{p^{-}}^{-}+s \varphi_{p_{-}}^{-}-j \omega_{p} \varphi_{p_{-}}^{-}
\end{aligned}
$$

Similarly, the PW positive and negative sequence components flux equations can be obtained by

$$
\begin{gathered}
\varphi_{p+}^{+}=L_{p} i_{p+}^{+}+M_{p r} i_{r+}^{+} \\
\varphi_{p-}^{-}=L_{p} i_{p-}^{-}+M_{p r} i_{r-}^{-} .
\end{gathered}
$$

A similar method can also be employed to derive the positive and negative sequence voltage and flux equations of the $\mathrm{CW}$ and rotor. And then, the dynamic vector model of the BDFIG under unbalanced loads can be decomposed into two sets of equations as follows:

$$
\begin{aligned}
& \left\{\begin{array}{l}
u_{p+}^{+}=R_{p} i_{p+}^{+}+s \varphi_{p+}^{+}+j \omega_{p} \varphi_{p+}^{+} \\
\varphi_{p+}^{+}=L_{p} i_{p+}^{+}+M_{p r} i_{r+}^{+} \\
u_{c+}^{+}=R_{c} i_{c+}^{+}+s \varphi_{c+}^{+}+j\left(\omega_{p}-\left(p_{p}+p_{c}\right) \omega_{r}\right) \varphi_{c+}^{+} \\
\varphi_{c+}^{+}=L_{c} i_{c+}^{+}+M_{c r} i_{r+}^{+} \\
u_{r+}^{+}=R_{r} i_{r+}^{+}+s \varphi_{r+}^{+}+j\left(\omega_{p}-P_{p} \omega_{r}\right) \varphi_{r+}^{+} \\
\varphi_{r+}^{+}=L_{r} i_{r+}^{+}+M_{p r} i_{p+}^{+}+M_{c r} i_{c+}^{+}
\end{array}\right. \\
& \left\{\begin{array}{l}
u_{p-}^{-}=R_{p} i_{p-}^{-}+s \varphi_{p-}^{-}-j \omega_{p} \varphi_{p-}^{-} \\
\varphi_{p-}^{-}=L_{p} i_{p-}^{-}+M_{p r} i_{r-}^{-} \\
u_{c-}^{-}=R_{c} i_{c-}^{-}+s \varphi_{c-}^{-}+j\left(-\omega_{p}-\left(p_{p}+p_{c}\right) \omega_{r}\right) \varphi_{c-}^{-} \\
\varphi_{c-}^{-}=L_{c-} i_{c-}^{-}+M_{c r} i_{r-}^{-} \\
u_{r-}^{-}=R_{r} i_{r-}^{-}+s \varphi_{r-}^{-}+j\left(-\omega_{p}-P_{p} \omega_{r}\right) \varphi_{r-}^{-} \\
\varphi_{r-}^{-}=L_{r} i_{r-}^{-}+M_{p r} i_{p-}^{-}+M_{c r} i_{c-}^{-}
\end{array}\right.
\end{aligned}
$$

where (17) and (18) are the positive and negative sequence components equations, respectively.

\section{Design of Control Scheme Under Unbalanced LOADS}

The control strategy for unbalanced loads consists of two parts; the first part represent the conventional DVC which control the frequency and amplitude of PW voltage in positive-sequence. The second part represents the proposed strategy to minimize the negative component of PW voltage.

\section{A. Conventional Direct Voltage Control}

In a standalone mode, the frequency and amplitude of the PW voltage must be stable when the rotor speed or load changes. To achieve that, the DVC is commonly used due to its robustness and simple to implement. Figure. 3 shows the block diagram of the conventional control scheme [19]. The DVC is achieved by tuning $i^{*}{ }_{c q}$ to zero. Thus, the $i^{*}{ }_{c d}$ represented the magnitude of the CW current. Thus, the PW voltage amplitude is controlled by $\mathrm{CW}$ current $i_{c d}$. The actual PW voltage amplitude $\left|U_{p}\right|$ can be expressed as

$$
\left|U_{p}\right|=\sqrt{u_{p d}^{2}+u_{p q}^{2}}
$$

To maintain the PW voltage angle equal to 50 hertz, the frequency of $\mathrm{CW}$ must be changed directly when the rotor speed changed.

\section{B. Proposed Control Strategy to Compensate the Unbalanced Effect of $P W$ voltage}

When the system works under unbalanced loads, the negative-sequence component exists in PW voltage. As a result, the PW voltage becomes unbalanced with twice PW frequency.

From (5)-(10), the relation between PW voltage and CW 
current in positive sequence can be expressed

$$
\begin{aligned}
i_{c}=\alpha_{2} i_{p}-\alpha_{4} \varphi_{p}-j\left(\alpha_{1} i_{p}-\alpha_{3} \varphi_{p}\right) /\left(\omega_{p}-p_{p} \omega_{r}\right) \\
\alpha_{1}=\left(R_{r} L_{p}\right) /\left(M_{p r} M_{c r}\right) \\
\alpha_{2}=\left(L_{p} L_{r \sigma p}\right) /\left(M_{p r} M_{c r}\right) \\
\alpha_{3}=R_{r} /\left(M_{p r} M_{c r}\right) \\
\alpha_{4}=L_{r} /\left(M_{p r} M_{c r}\right) \\
\sigma_{p}=1-M_{p r}^{2} / L_{r} L_{p} .
\end{aligned}
$$

From (20), the relation between CW current and PW current in negative sequence component can be expressed as

$$
\begin{aligned}
& i_{c-}^{-}=\alpha_{2} i_{p-}^{-}-\alpha_{4} \varphi_{p-}^{-}+j\left(\alpha_{1} i_{p-}^{-}-\alpha_{3} \varphi_{p-}^{-}\right) /\left(\omega_{p}+p_{p} \omega_{r}\right) \\
& i_{p-}^{-}=\left(i_{c-}^{-}+\alpha_{4} \varphi_{p-}^{-}+j \frac{\alpha_{3} \varphi_{p-}^{-}}{\omega_{p}+p_{p} \omega_{r}}\right) /\left(\alpha_{2}+j \frac{\alpha_{1}}{\omega_{p}+p_{p} \omega_{r}}\right) .
\end{aligned}
$$

The equation of PW voltage in negative sequence (18) can be represented in $d q$ reference frame as $u_{p-}^{-d q}=R_{p} i_{p-}^{-d q}+s\left(L_{p} i_{p}^{-d q}+M_{p r} i_{r}^{-d q}\right)-j \omega_{p}\left(L_{p} i_{p-}^{-d q}+M_{p r} i_{r-}^{-d q}\right)$

When the derivative terms are equal to zero in steady state, (28) expressed as

$$
u_{p-}^{-d q}=R_{p} i_{p-}^{-d q}-j \omega_{p}\left(L_{p} i_{p-}^{-d q}+M_{p r} i_{r-}^{-d q}\right) .
$$

Substituting (27) into (29), to find the relation between PW voltage and $\mathrm{CW}$ current in negative sequence as following:

$$
\begin{aligned}
& u_{p-}^{-d q}= \\
& \frac{\left(R_{p}-j \omega_{p} L_{p}\right)\left(i_{c-}^{-d q}+\alpha_{4}\left(L_{p} i_{p-}^{-d q}+M_{p r} i_{r-}^{-d q}\right)+j \frac{\alpha_{3}\left(L_{p} i_{p-}^{-d q}+M_{p r} i_{r-}^{-d q}\right)}{\omega_{p}+p_{p} \omega_{r}}\right)}{\left(\alpha_{2}+j \frac{\alpha_{1}}{\omega_{p}+p_{p} \omega_{r}}\right)} .
\end{aligned}
$$$$
-j \omega_{p} M_{p r} i_{r-}^{-d q}
$$

From (30), if the negative sequence (currents of PW and rotor) are considered as an additive perturbation, the PW voltage in negative sequence is controlled by regulating $\mathrm{CW}$ current in negative sequence because of their linear relationship.

From Fig. 4, the dual second-order generalized integrators (DSOGI) is used to extract PW voltage in negative sequence [20], and PI controllers are applied to obtain the CW current which compensate the PW voltage in negative sequence. Therefore, the references of $\mathrm{CW}$ currents in negative frame can be expressed as

$$
\begin{aligned}
& i_{c d-}^{-}=\left(K_{p}+\frac{K_{i}}{s}\right)\left(0-u_{p d-}^{-}\right) \\
& i_{c q-}^{-}=\left(K_{p}+\frac{K_{i}}{s}\right)\left(u_{p q-}^{-}-0\right)
\end{aligned}
$$

where $K_{p}$ is the proportional gain and $K_{i}$ is the integral gain.

The new CW current in the negative frame should be added to the $\mathrm{CW}$ current reference in the positive frame. Therefore, the new $\mathrm{CW}$ currents are transformed into coordinates, the positive frame by using twice PW angle $2 \theta_{p}$. Equation (33) represents the total reference $\mathrm{CW}$ current in the positive frame.

$$
\begin{aligned}
& i_{c d q}^{+*}=i_{c d q+}^{+*}+i_{c d q-}^{+^{*}} \\
& =i_{c d q+}^{+*}+\underbrace{i_{c d q-}^{+^{*}} e^{-j 2 \omega_{p} t}}_{\text {Negative sequence component }}
\end{aligned}
$$

Due to presence negative component value in $\mathrm{CW}$ current commands, the PI controller can't achieve a good regulate of $\mathrm{CW}$ current commands, therefore the resonant $(\mathrm{R})$ controller is adopted with PI controller to accurately regulate these $\mathrm{CW}$ currents, PI deal with $\mathrm{CW}$ current in positive sequence to regulate the $\mathrm{PW}$ voltage magnitude and $\mathrm{R}$ deal with $\mathrm{CW}$ current in the negative sequence to balance the PW voltage.

Figure 5 shows the block diagram of the DSOGI, which consists of two quadrature signal generators (QSGs) based on the SOGI and the positive-negative signal calculator (PNSC). The two SOGI-QSGs are applied to generate quadrature signals both for $u_{p \alpha}$ and $u_{p \beta}$. The PNSC is used to extract negative and positive component of PW voltage in $\alpha \beta$ frame.

From PNSC, the positive and negative component of PW voltage in $\alpha \beta$ frame can be calculated as

$$
\begin{aligned}
& u_{p \alpha+}^{+}=u_{p \alpha}^{\prime}-q u_{p \beta}^{\prime} \\
& u_{p \beta+}^{+}=q u_{p \alpha}^{\prime}+u_{p \beta}^{\prime} \\
& u_{p \alpha-}^{-}=q u_{p \beta}^{\prime}+u_{p \alpha}^{\prime} \\
& u_{p \beta-}^{-}=u_{p \beta}^{\prime}-q u_{p \alpha}^{\prime}
\end{aligned}
$$

where $q=e^{-j(\pi / 2)}$ represents a phase-shift operator in the time-domain to acquire quadrature-phase waveform, the superscript ' indicate to quadrature generator.

In Fig. 4, the PI parameters are tuned by the classic ZieglerNichols method described in [21], and the parameter design of the DSOGI can refer to [22].

\section{RESUlTS AND DisCUSSIONS}

\section{A. Simulation Results}

The simulation was implemented in MATLAB/Simulink environment. The details of parameters used in the test platform are given in Table II. A three-phase unbalanced load (12 $\Omega, 12 \Omega$, and $6 \Omega$ in the three phases) is used to test the performance of the proposed method. Three different simulation scenarios are considered to test the effectiveness of the proposed method under a three-phase unbalanced load.

Firstly, the performance of the proposed control method is investigated at the sub-synchronous speed of $600 \mathrm{rpm}$ and compared with that of the conventional method, as shown in Fig. 6.

With the conventional method, the PW line voltage is unbalanced. The amplitude of negative-sequence PW voltage reach an average value of around $25 \mathrm{~V}$, which can be calculated by

$$
\left|U_{p-}^{-}\right|=\sqrt{\left(u_{p d-}^{-}\right)^{2}+\left(u_{p q_{-}}^{-}\right)^{2}} .
$$

With the proposed method, the amplitude of the negativesequence PW voltage can be significantly decreased to an average value of around $5 \mathrm{~V}$. As a result, the PW line voltage becomes nearly balanced. The distortion of the $\mathrm{CW}$ phase current is significantly increased with the proposed method, 


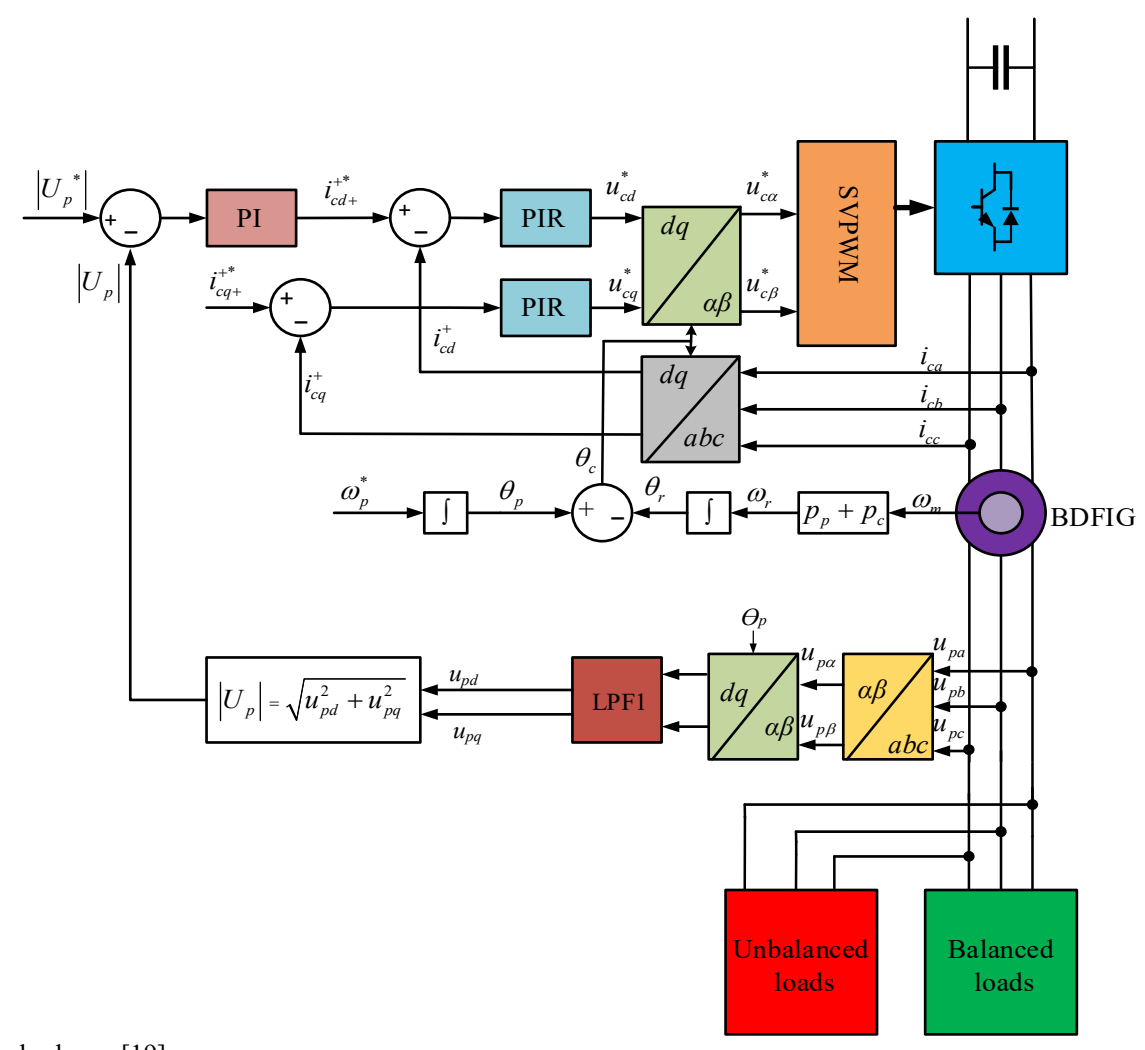

Fig. 3. Conventional control scheme [19].

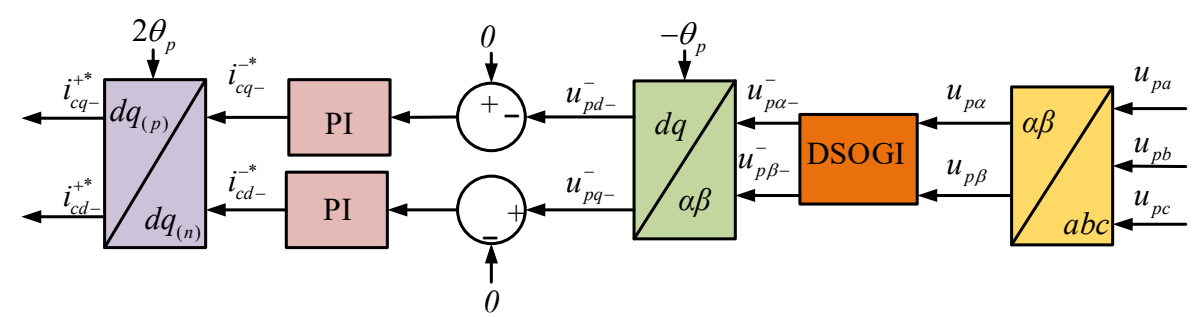

Fig. 4. Block diagram of the proposed negative sequence voltage compensator.

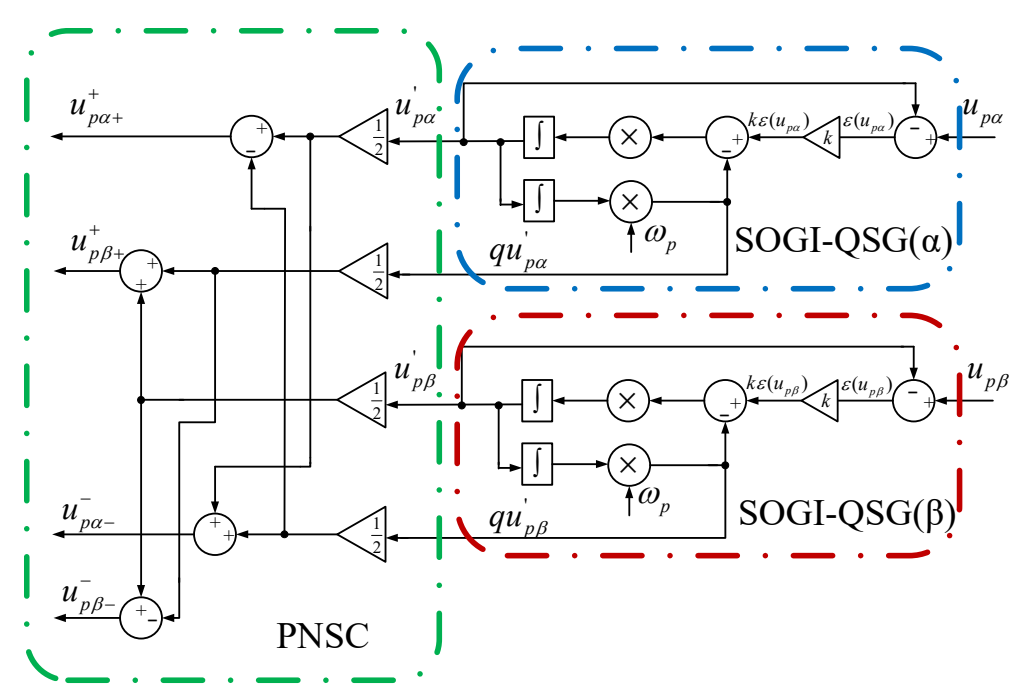

Fig. 5. Block diagram of the DSOGI. 
TABLE II

MAIN PARAMETERS OF THE PROTOTYPE BDFIG

\begin{tabular}{llll}
\hline \hline PARAMETER & VALUE & PARAMETER & VALUE \\
\hline Capacity & $30 \mathrm{kVA}$ & $R_{c}$ & $0.26803 \Omega$ \\
Speed range & $600 \sim 1200 \mathrm{rpm}$ & $R_{r}$ & $0.33385 \Omega$ \\
PW pole pairs & 1 & $L_{p}$ & $0.47492 \mathrm{H}$ \\
CW pole pairs & 3 & $L_{c}$ & $0.032156 \mathrm{H}$ \\
PW rated voltage & $380 \mathrm{~V}$ & $L_{r}$ & $0.22523 \mathrm{H}$ \\
PW rated current & $45 \mathrm{~A}$ & $L_{p r}$ & $0.30685 \mathrm{H}$ \\
CW voltage range & $0 \sim 350 \mathrm{~V}$ & $M_{c r}$ & $0.025840 \mathrm{H}$ \\
CW current range & $0 \sim 60 \mathrm{~A}$ & Rotor type & Wound rotor \\
$R_{p}$ & $0.40335 \Omega$ & & \\
\hline \hline
\end{tabular}

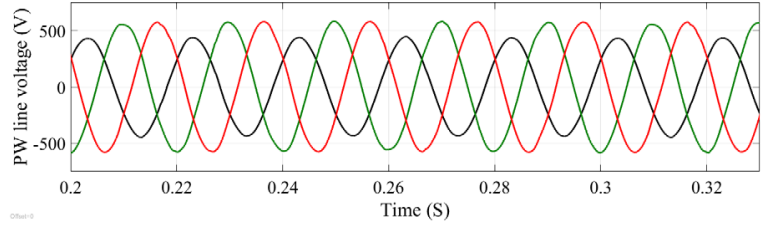

$\left(a_{1}\right)$

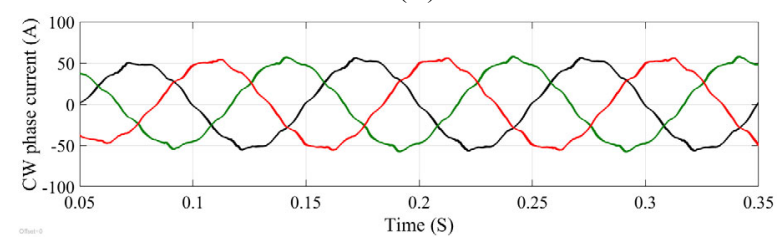

$\left(b_{1}\right)$

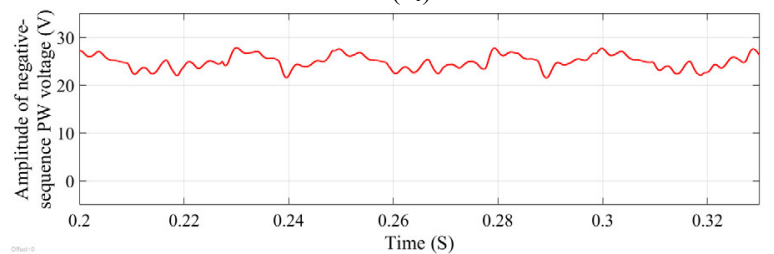

$\left(c_{1}\right)$

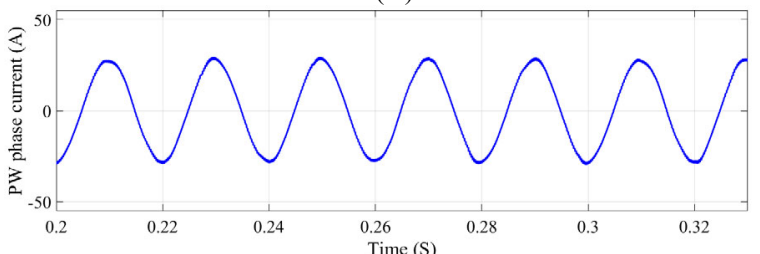

$\left(d_{1}\right)$

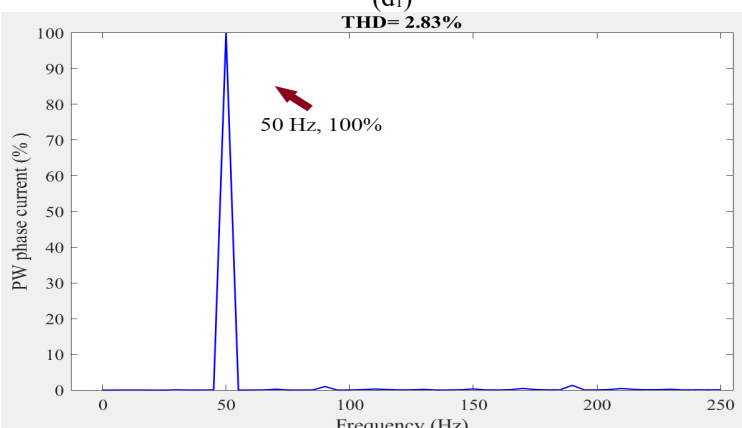

$\left(e_{1}\right)$

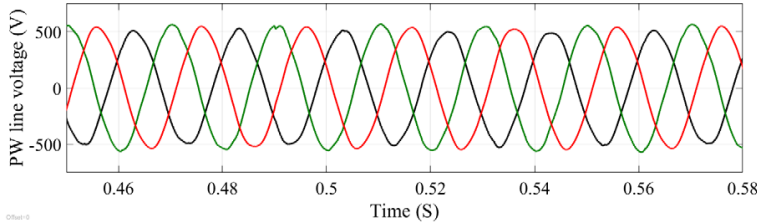

$\left(\mathrm{a}_{2}\right)$

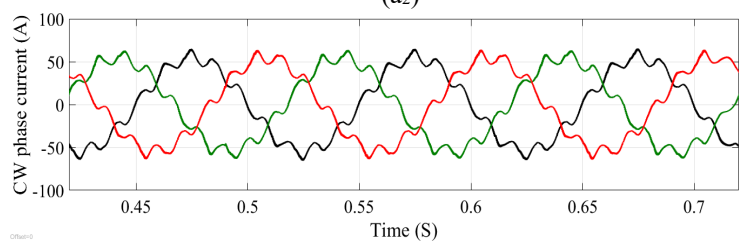

$\left(\mathrm{b}_{2}\right)$

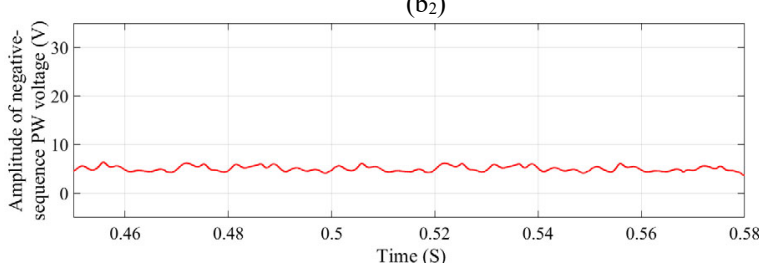

$\left(\mathrm{c}_{2}\right)$

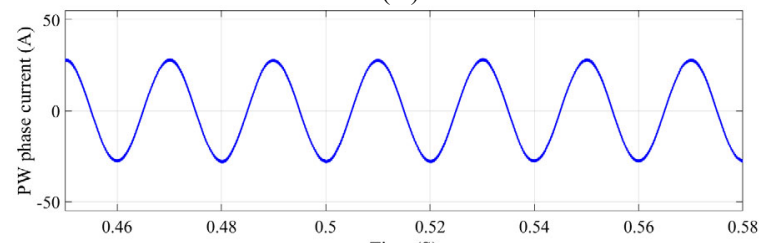

$\left(\mathrm{d}_{2}\right)$

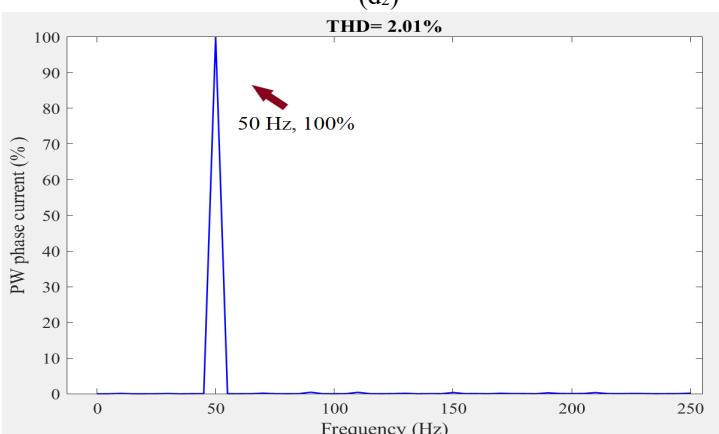

$\left(\mathrm{e}_{2}\right)$

Fig. 6. Simulation results with a three-phase unbalanced load at the rotor speed of $600 \mathrm{rpm}$ (subscript 1 indicates the conventional method and subscript 2 the proposed method): (a) PW line voltage, (b) CW phase current, (c) amplitude of the negative-sequence PW voltage, (d) PW phase current, and (e) THD and harmonic spectrum of the PW current as shown in (d). 
due to the existence of the compensation component for the negative-sequence PW voltage. Figures. $6\left(\mathrm{~d}_{1}\right),\left(\mathrm{e}_{1}\right),\left(\mathrm{d}_{2}\right)$ and $\left(\mathrm{e}_{2}\right)$ show the PW phase currents and their harmonic spectrums under the conventional and the proposed methods. The THD of the PW phase current reaches $2.83 \%$ with the conventional method and $2.01 \%$ with the proposed method. Comparing Fig. 6(e1) with Fig. 6(e2), it can be noted that the proposed method does not significantly increase or reduce distortion in the PW current.

Secondly, Fig. 7 shows the results at the super-synchronous speed of $900 \mathrm{rpm}$. The results of PW line voltage, CW phase current, amplitude of the negative-sequence PW voltage, PW phase current, and THD and harmonic spectrum of the PW current are almost similar to the results under the subsynchronous speed of $600 \mathrm{rpm}$, which means that the proposed method demonstrates a good performance under sub- and super-synchronous speeds.

Finally, the third simulation is carried out to check the dynamic performance of the proposed method under the variable speed from the super- to sub-synchronous speed. The corresponding simulation results are shown in Fig. 8. The BDFIG is started under the three-phase unbalanced load and at the super-synchronous speed of $900 \mathrm{rpm}$ with the conventional method. Consequently, the PW line voltage becomes unbalanced and the amplitude of the negative-sequence PW voltage reaches around $23 \mathrm{~V}$.

At $0.4 \mathrm{~s}$, the proposed negative sequence voltage compensator is activated, which results that the amplitude of the negative-sequence PW voltage is significantly reduced from 23 to $3 \mathrm{~V}$ within $0.04 \mathrm{~s}$. Consequently, the PW line voltage becomes balanced. And then, at $0.6 \mathrm{~s}$, the speed begins to drop down from 900 to $600 \mathrm{rpm}$. As it can be seen from Fig. 8 , the proposed control method maintains the balanced PW voltage during the speed variation.

\section{B. Experimental Setup}

Figure 9 present the prototype experimental setup based on a $30 \mathrm{kVA}$ BDFIG, whose main parameters can be found in Table II. A $37 \mathrm{~kW}$ three-phase induction motor is used as the prime mover of the BDFIG. A back-to-back converter with DSP TMS28335 based control circuit is used to interconnect the PW and the CW. Two type of loads are considered in this paper: a three-phase unbalanced load $(12 \Omega, 12 \Omega$, and $6 \Omega$ in three phases) and a single-phase load with resistance of $12 \Omega$ is linked between phases $a$ and $b$ of the PW. The single phase load leads to generate large unbalanced effect when comparing with a three-phase unbalanced load, therefore, when compensating the significant unbalanced effect of a single phase load, this gives more reliability for the proposed control scheme.

\section{Results with Three-Phase Unbalanced Load}

Three different scenarios are considered to test the effectiveness of the proposed method under a three-phase unbalanced load. The performance of the proposed control technique is investigated at sub-synchronous speed $600 \mathrm{rpm}$ and compared with that of the conventional one, as shown in
Fig. 10. The conventional and the proposed methods are separately activated in the two different experiments.

With the conventional method, the PW line voltage and PW phase current are unbalanced. The amplitude of negativesequence PW voltage reach an average of around $20 \mathrm{~V}$. With the proposed method, the amplitude of negative-sequence PW voltage decreased significantly to reach an average of around $5 \mathrm{~V}$, as a result, the PW line voltage becomes balanced. Figures 10(b1), (e1), (b2) and (e2) shows the PW phase currents and their harmonic spectrums under the conventional and the proposed methods. The THD of the PW phase current reaches $5.76 \%$ with the conventional method and $4.90 \%$ with the proposed method. Comparing Fig. 10(e1) with Fig. 10(e2), it can be noted that the proposed method does not significantly increase or reduce distortion in the PW current.

Figure 11 shows the results at super-synchronous speed 900 $\mathrm{rpm}$. With the proposed method, the total harmonic distortion (THD) of CW phase current is increased significantly, due to existence the compensated value of negative-sequence of $\mathrm{PW}$ line voltage. Figures $11\left(b_{1}\right),\left(d_{1}\right),\left(b_{2}\right)$ and $\left(d_{2}\right)$ shows the $C W$ phase current and details of the THD and harmonic spectrum of the CW phase current. The THD reaches $18.51 \%$ with the conventional method and $73.60 \%$ with the proposed method. Figures 11(e1), (f1), (e2) and (f2) shows the PW phase currents and their harmonic spectrums under the conventional and the proposed methods. The THD of the PW phase current reaches $5.59 \%$ with the conventional method and 5.03\% with the proposed method. Comparing Fig. 11(e1) with Fig. 11(e2), it can be noted that the proposed method does not significantly increase or reduce distortion in the PW current. The results of PW line voltage and amplitude of negative-sequence PW voltage are almost similar with the results under subsynchronous speed $600 \mathrm{rpm}$, which means that, the proposed method demonstrated a good performance under sub and super synchronous speeds.

For more evaluate of the performance quality of the proposed strategy, the third experiment is carried out to check the dynamic performance of the proposed technique with variable speed from super-synchronous speed to subsynchronous speed. From Fig. 12 the BDFIG begins under three phase unbalanced load and at super-synchronous speed $900 \mathrm{rpm}$ with the conventional method, the PW line voltage becomes unbalanced and amplitude of negative-sequence PW voltage reach at around $20 \mathrm{~V}$. At $3.15 \mathrm{~s}$, the proposed method inserted into control scheme. Since the DSOGI in the negative sequence voltage compensator can act as a filter, the $\mathrm{CW}$ compensation current can be smoothly increased and consequently inrush current in $\mathrm{CW}$ current dose not be generated during switching from the conventional to proposed method. The amplitude of negative-sequence PW voltage decreased significantly from $20 \mathrm{~V}$ to reach at around $5 \mathrm{~V}$ within around $0.25 \mathrm{~s}$, as a result, the PW line voltage becomes balanced. The speed begins deceleration from 900 to $680 \mathrm{rpm}$ in $5.6 \mathrm{~s}$. From Fig. 12, the proposed strategy maintains the balance of PW line voltage during the speed variation. 


\section{Results with Single Phase Load}

A single-phase load is used to achieve the large unbalanced effect of PW line voltage, which makes the BDFIG works under tough and harmful condition with a PW voltage of 150 $\mathrm{V}$. Deceleration and acceleration for rotor speed are applied to evaluate the performance dynamic.

From Fig. 13, the BDFIG begins under single-phase load at super-synchronous speed $900 \mathrm{rpm}$ with the conventional method, the PW line voltage becomes unbalanced and amplitude of negative-sequence PW voltage reached at around $80 \mathrm{~V}$. At $2 \mathrm{~s}$, the proposed method inserted into control scheme. Therefore, the amplitude of negative-sequence PW

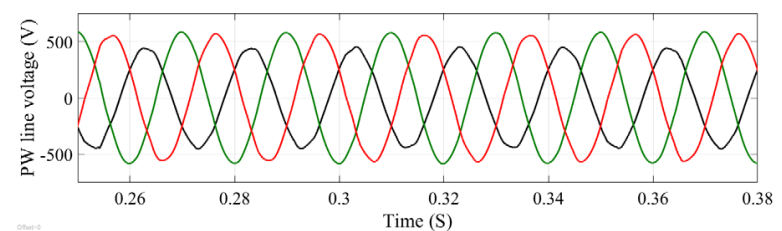

(a1)

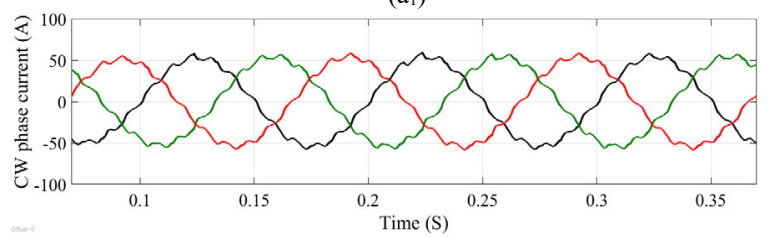

$\left(b_{1}\right)$

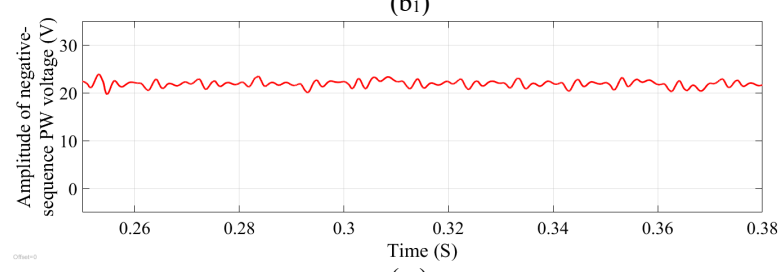

$\left(\mathrm{c}_{1}\right)$

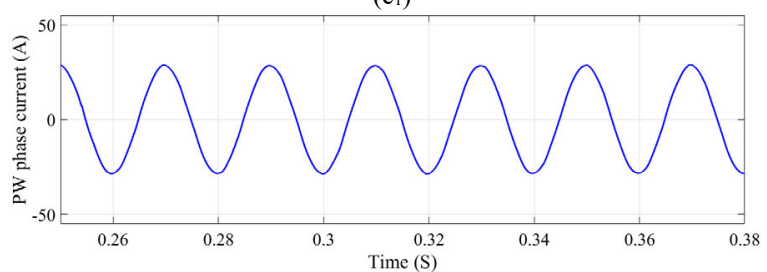

$\left(\mathrm{d}_{1}\right)$

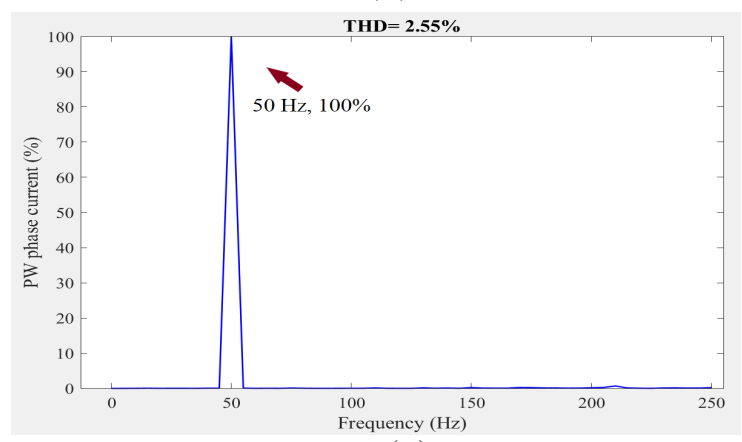

$\left(\mathrm{e}_{1}\right)$

Fig. 7. Simulation results with a three-phase unbalanced load at the rotor speed of $900 \mathrm{rpm}$ (subscript 1 indicates the conventional method and subscript 2 the proposed method): (a) PW line voltage, (b) CW phase current, (c) amplitude of the negative-sequence PW voltage, (d) PW phase current, and (e) THD and harmonic spectrum of the PW current as shown in (d). voltage decreased significantly from $80 \mathrm{~V}$ to reached at around $20 \mathrm{~V}$ within around $0.9 \mathrm{~s}$, as a result, the PW line voltage becomes mostly balanced. To evaluate the dynamic performance, the rotor speed decelerated from super synchronous speed $900 \mathrm{rpm}$ at $4.7 \mathrm{~s}$ to reach sub-synchronous speed $630 \mathrm{rpm}$ in $6 \mathrm{~s}$, and acceleration from sub-synchronous speed $630 \mathrm{rpm}$ in $7.8 \mathrm{~s}$ to reach super-synchronous speed 900 rpm in $9.1 \mathrm{~s}$.

From Figs. 13(a) and (d), the proposed strategy can maintain voltage balancing of PW during the speed variation. Figures 13(e) and (f) present the extended sceneries of PW line voltage with conventional method and proposed strategy,

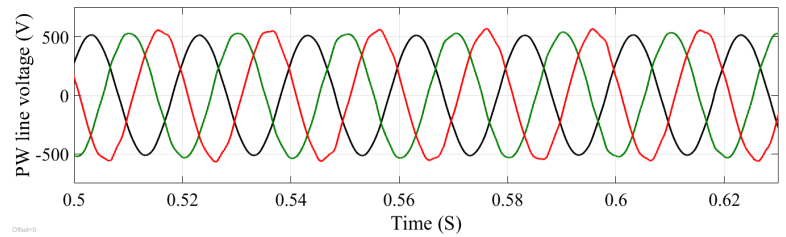

$\left(\mathrm{a}_{2}\right)$

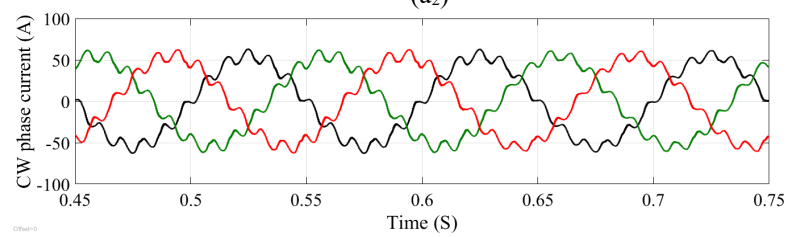

(b)

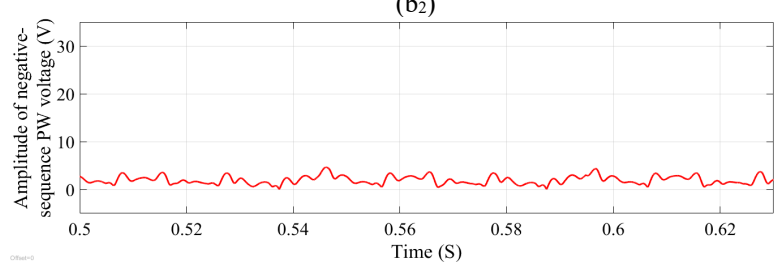

$\left(\mathrm{c}_{2}\right)$

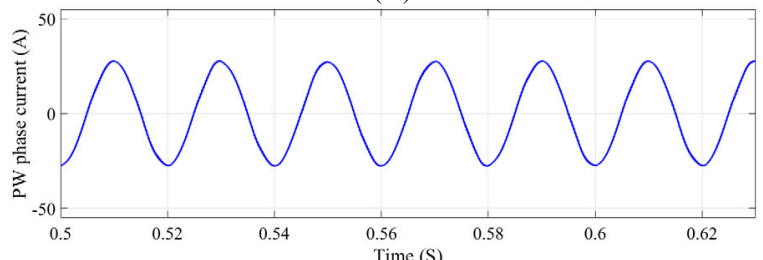

$\left(\mathrm{d}_{2}\right)$

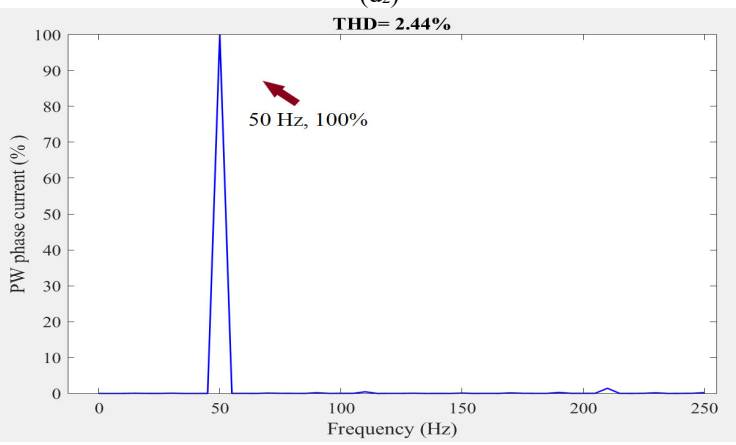

$\left(\mathrm{e}_{2}\right)$ 


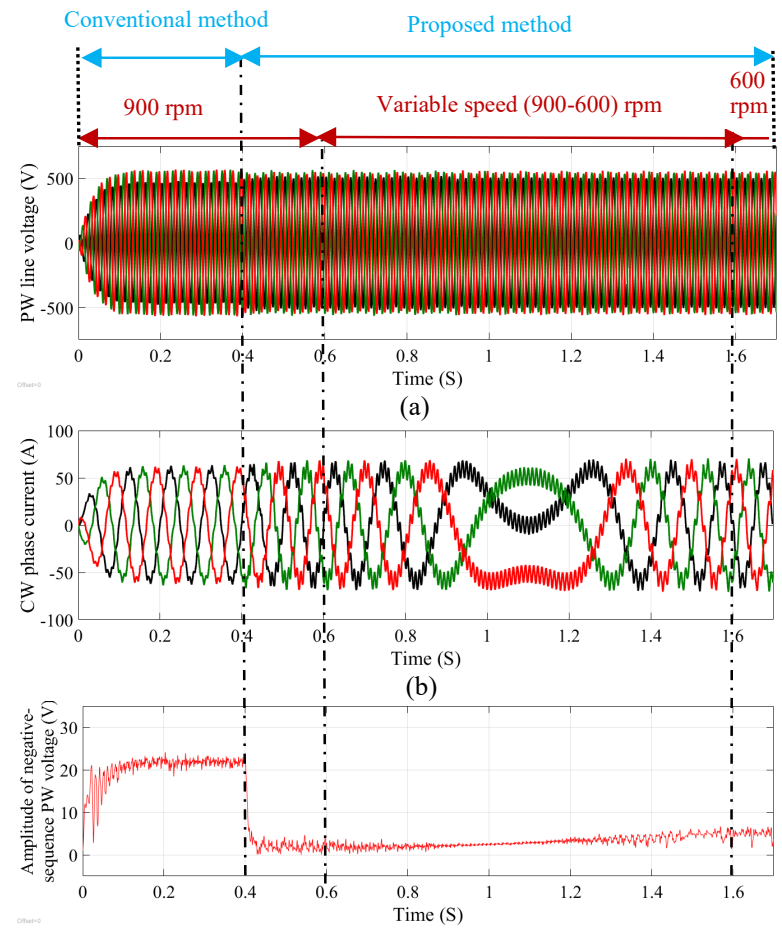

(c)

Fig. 8. Simulation results with a three-phase unbalanced load under the variable rotor speed: (a) PW line voltage, (b) CW phase current, and (c) amplitude of the negative-sequence PW voltage.

which illustrates the superiority of the proposed strategy over the conventional method to compensate the large unbalanced effect of PW line voltage. Figures 13(b) and (g) show the overall and extended sceneries of PW phase current, due to the influence of the single phase load the PW phase current works with two phases and the third phase suppression to works as a direct current with a small value. As a result of compensating the unbalanced PW voltage, the $\mathrm{CW}$ phase current contains many harmonics. Figures 13(h) and (i) illustrate the extended scenery of CW phase current and the details of the harmonic spectrum and THD, respectively. The fundamental frequency of $\mathrm{CW}$ current is $10 \mathrm{~Hz}$, the harmonic component is with the frequency of $110 \mathrm{~Hz}$, and the THD reaches $112.87 \%$.

\section{CONCLUSION}

In this paper, the unbalanced effect of PW line voltage is discussed comprehensively. The negative sequence component represents the unbalanced effect of PW line voltage in the standalone operation of BDFIG. The failure of the conventional DVC to support unbalanced loads has been demonstrated. To minimize this problem, a negative sequence compensator in MSC is proposed to compensate the unbalance effect of PW line voltage. To present comprehensive experimental results, two type of loads (three-phase resistive load and single-phase load) are considered to implement experiments under different operation mods of the BDFIG. The performance of the proposed strategy has been compared with that of the conventional methods. The simulation and experimental results proved performance of proposed control strategy. The low-order harmonic components in PW line voltage would be investigated in the future to support BDFIG under nonlinear loads.

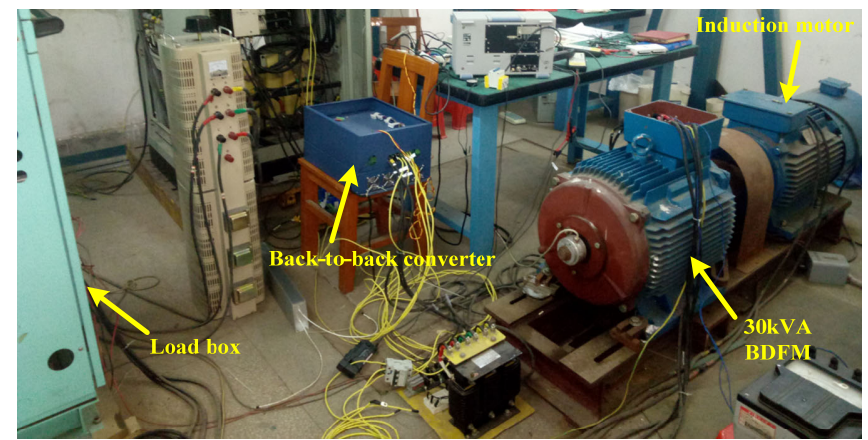

Fig. 9. Photograph of the experimental test platform.

\section{REFERENCES}

[1] L. Sun, Y. Chen, J. Su, D. Zhang, L. Peng, and Y. Kang, "Decoupling network design for inner current loops of stand-alone brushless doubly fed induction generation power system," IEEE Trans. Power Electron., vol. 33, no. 2, pp. 957-963, Feb. 2018.

[2] A. Zhang, X. Wang, W. Jia, and Y. Ma, "Indirect stator-quantities control for the brushless doubly fed induction machine," IEEE Trans. Power Electron., vol. 29, no. 3, pp. 1392-1401, Mar. 2014.

[3] G. Zhang, J. Yang, Y. Sun, M. Su, W. Tang, Q. Zhu, and H. Wang, "A robust control scheme based on ISMC for the brushless doubly fed induction machine," IEEE Trans. Power Electron., vol. 33, no. 4, pp. 3129-3140, Apr. 2018.

[4] R. Zhao, A. Zhang, Y. Ma, X. Wang, J. Yan, and Z. Ma, "The dynamic control of reactive power for the brushless doubly fed induction machine with indirect stator-quantities control scheme," IEEE Trans. Power Electron., vol. 30, no. 9, pp. 5046-5057, Sep. 2015.

[5] S. Shao, E. Abdi, F. Barati, and R. McMahon, "Stator-flux-oriented vector control for brushless doubly-fed induction generator," IEEE Trans. Ind. Electron., vol. 56, no. 10, pp. 4220-4228, Oct. 2009.

[6] T. Long, S. Shao, P. Malliband, E. Abdi, and R. A. McMahon, "Crowbarless fault ride-through of the brushless doubly fed induction generator in a wind turbine under symmetrical voltage dips," IEEE Trans. Ind. Electron., vol. 60, no. 7, pp. 2833-2840, Jul. 2013.

[7] T. Long, S. Shao, E. Abdi, R. A. McMahon, and S. Liu, "Asymmetrical low-voltage ride through of brushless doubly fed induction generators for the wind power generation," IEEE Trans. Energy Convers., vol. 28, no. 3 , pp. 502-511, Sep. 2013.

[8] R. Sadeghi, S. M. Madani, M. Ataei, M. R. A. Kashkooli, and S. Ademi, "Super-twisting sliding mode direct power control of a brushless doubly fed induction generator," IEEE Trans. Ind. Electron., vol. 65, no. 11, pp. 9147-9156, Nov. 2018.

[9] S. Shao, T. Long, E. Abdi, and R. A. McMahon, "Dynamic control of the brushless doubly fed induction generator under unbalanced operation," IEEE Trans. Ind. Electron., vol. 60, no. 6, pp. 2465-2476, Jun. 2013.

[10] J. Chen, W. Zhang, B. Chen, and Y. Ma, "Improved vector control of brushless doubly fed induction generator under unbalanced grid conditions for offshore wind power generation," IEEE Trans. Energy Convers., vol. 31, no. 1, pp. 293-302, Mar. 2016.

[11] T. Wu, X. Wang, and Y. Li, "The scalar control research based on fuzzy PID of BDFM stand-alone power generation system." in Proc. Int. Conf. Electr. Inf. Control Eng., 2011, pp. 2806-2809.

[12]Y. Liu, W. Ai, B. Chen, K. Chen, and G. Luo, "Control design and experimental verification of the brushless doubly-fed machine for standalone power generation applications," IET Elect. Power Appl., vol. 10, no. 1, pp. 25-35, Jan. 2016. 


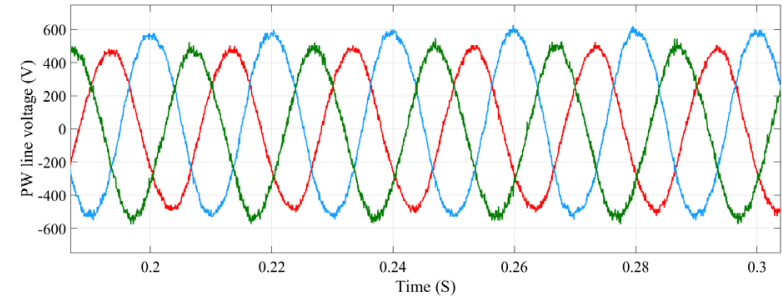

$\left(\mathrm{a}_{1}\right)$

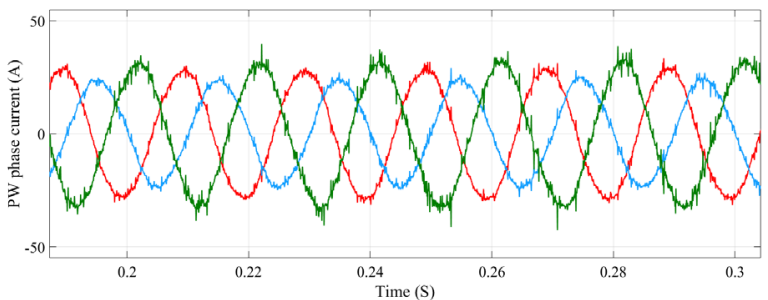

$\left(b_{1}\right)$

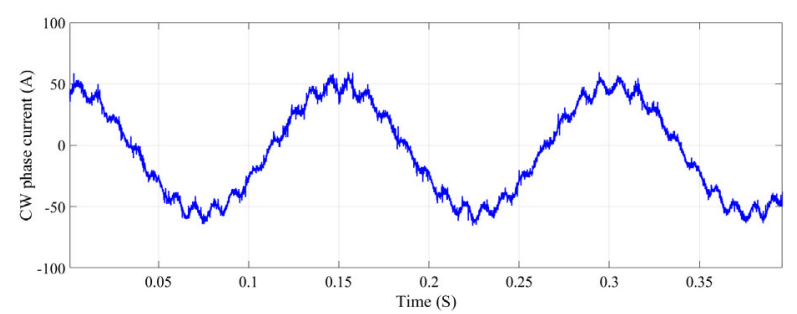

$\left(c_{1}\right)$

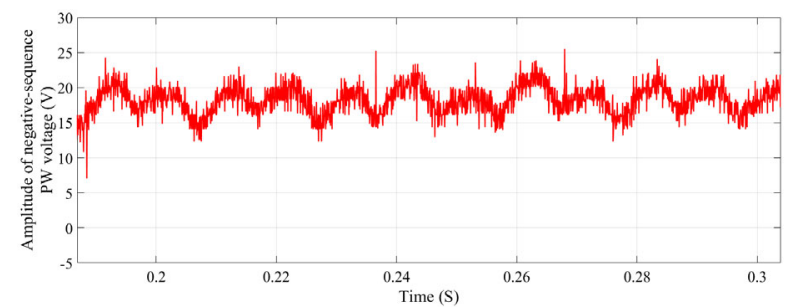

$\left(d_{1}\right)$

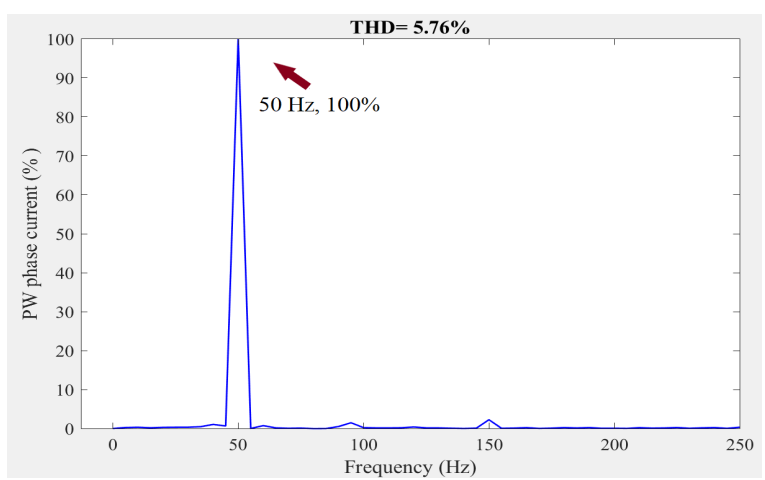

$\left(\mathrm{e}_{1}\right)$

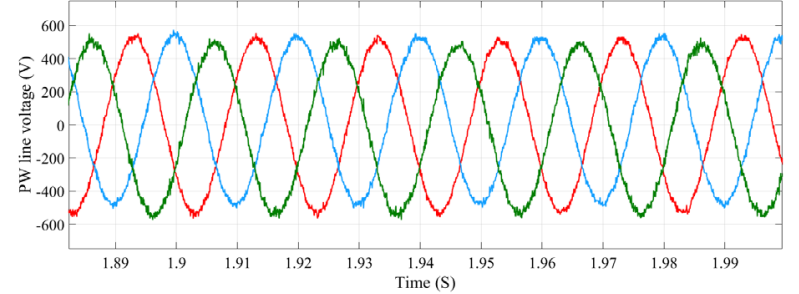

$\left(\mathrm{a}_{2}\right)$

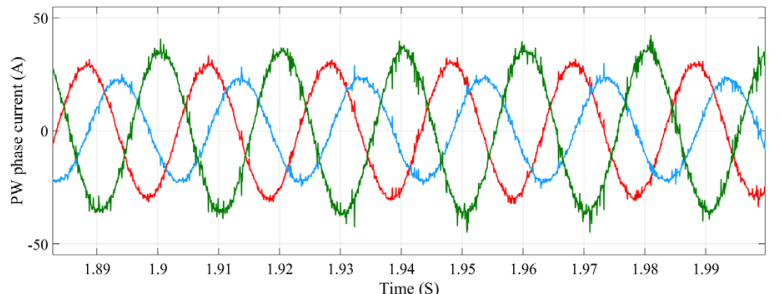

$\left(b_{2}\right)$

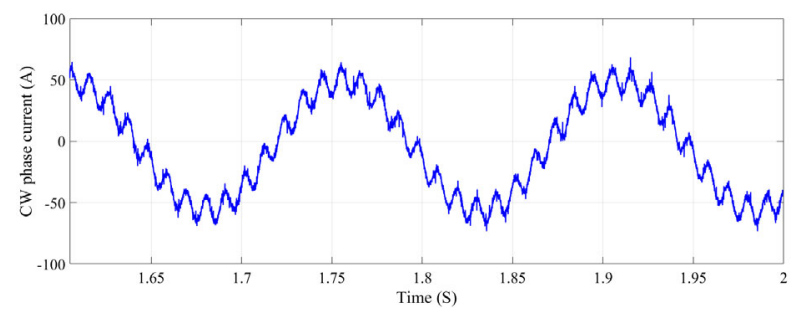

$\left(c_{2}\right)$

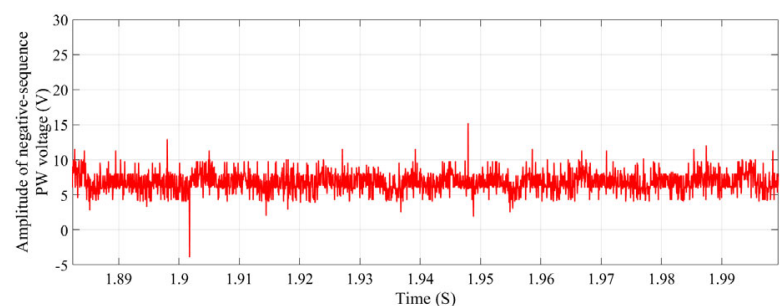

$\left(\mathrm{d}_{2}\right)$

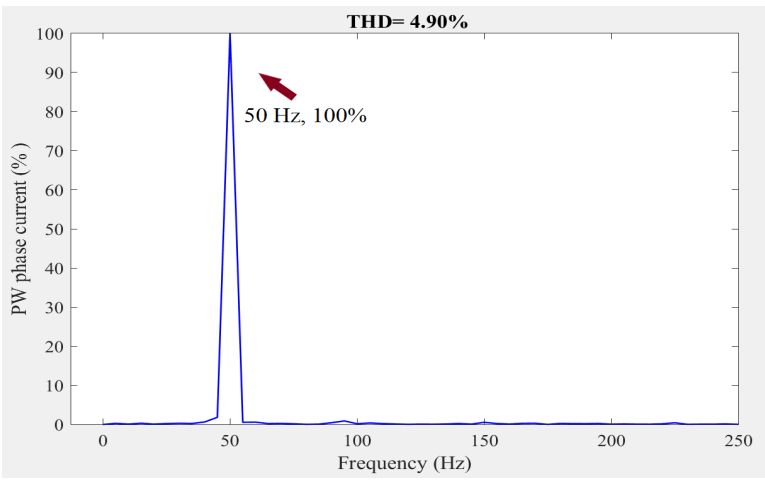

$\left(\mathrm{e}_{2}\right)$

Fig. 10. Experimental results with a three-phase unbalanced load at the rotor speed of $600 \mathrm{rpm}$ (the subscript 1 indicates the conventional method, and the subscript 2 the proposed method): (a) PW line voltage, (b) PW phase current, (c) CW phase current, (d) amplitude of negative sequence PW voltage, and (e) THD and harmonic spectrum of the PW current shown in (b). 


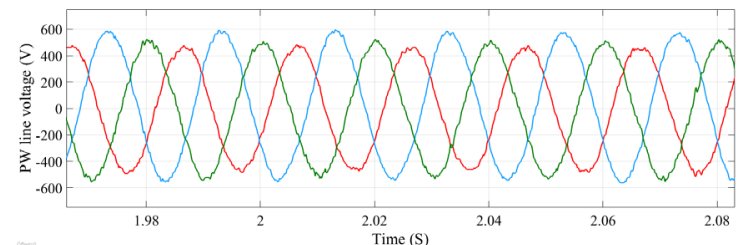

$\left(\mathrm{a}_{1}\right)$

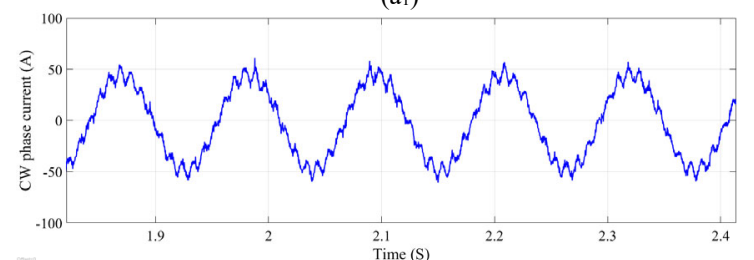

(b)

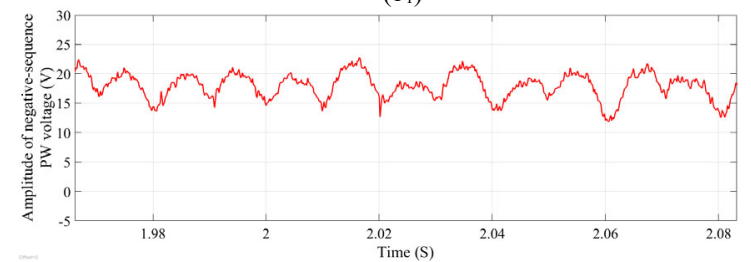

$\left(c_{1}\right)$

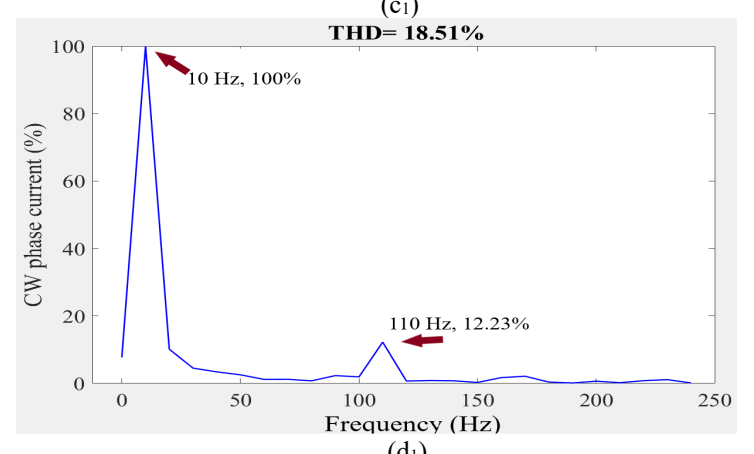

$\left(d_{1}\right)$

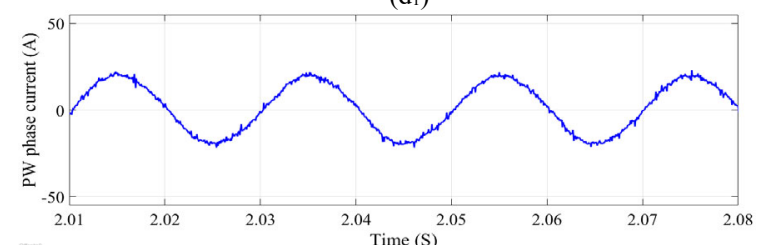

$\left(\mathrm{e}_{1}\right)$

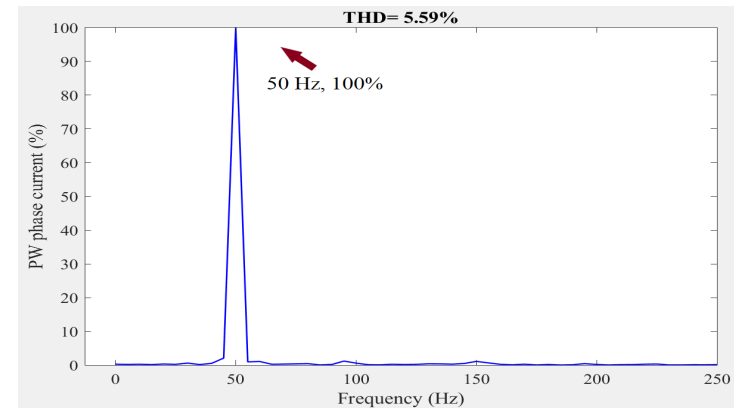

$\left(f_{1}\right)$

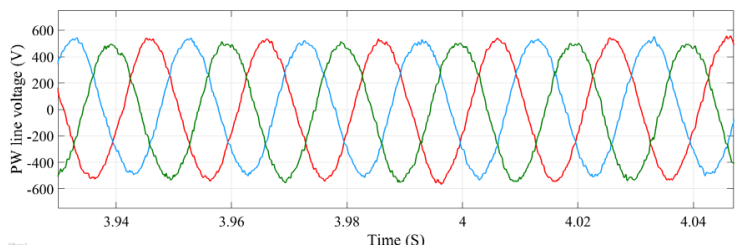

$\left(a_{2}\right)$

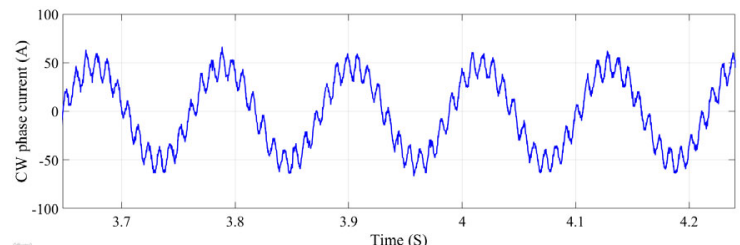

(b2)

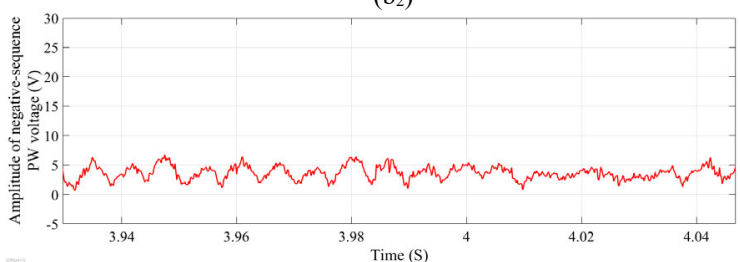

$\left(c_{2}\right)$

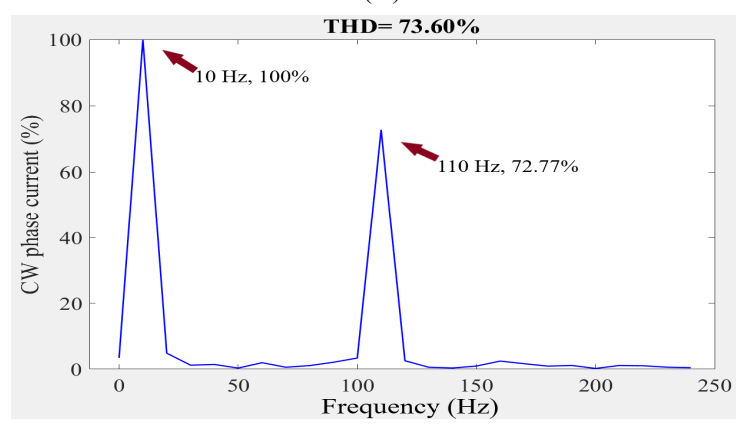

$\left(d_{2}\right)$

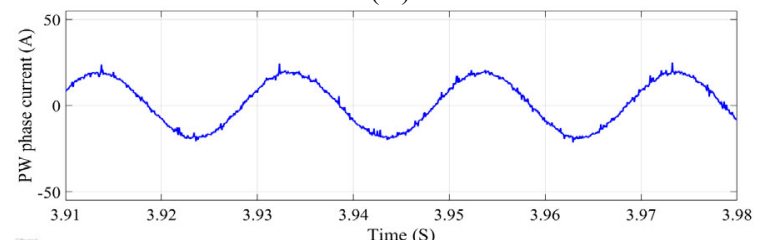

$\left(\mathrm{e}_{2}\right)$

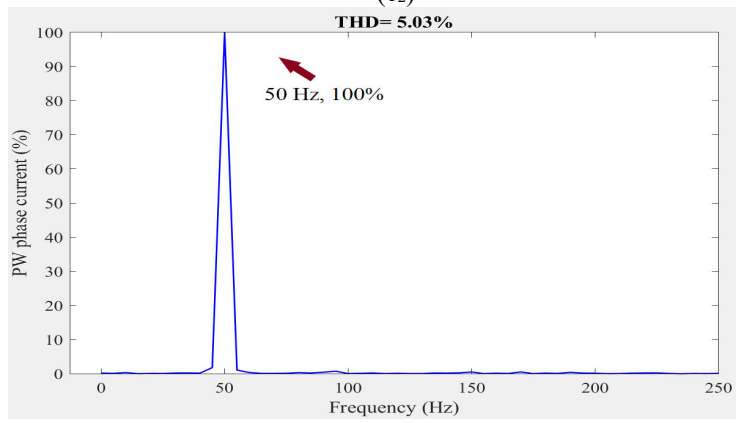

$\left(\mathrm{f}_{2}\right)$

Fig. 11. Experimental results with three-phase unbalanced load at $900 \mathrm{rpm}$ (subscript 1 indicates conventional method and subscript 2 indicates proposed method): (a) PW line voltage, (b) CW phase current, (c) amplitude of negative-sequence PW voltage, (d) THD and harmonic spectrum of the CW phase current, (e) PW phase current, and (f) THD and harmonic spectrum of the PW current shown in (e). 


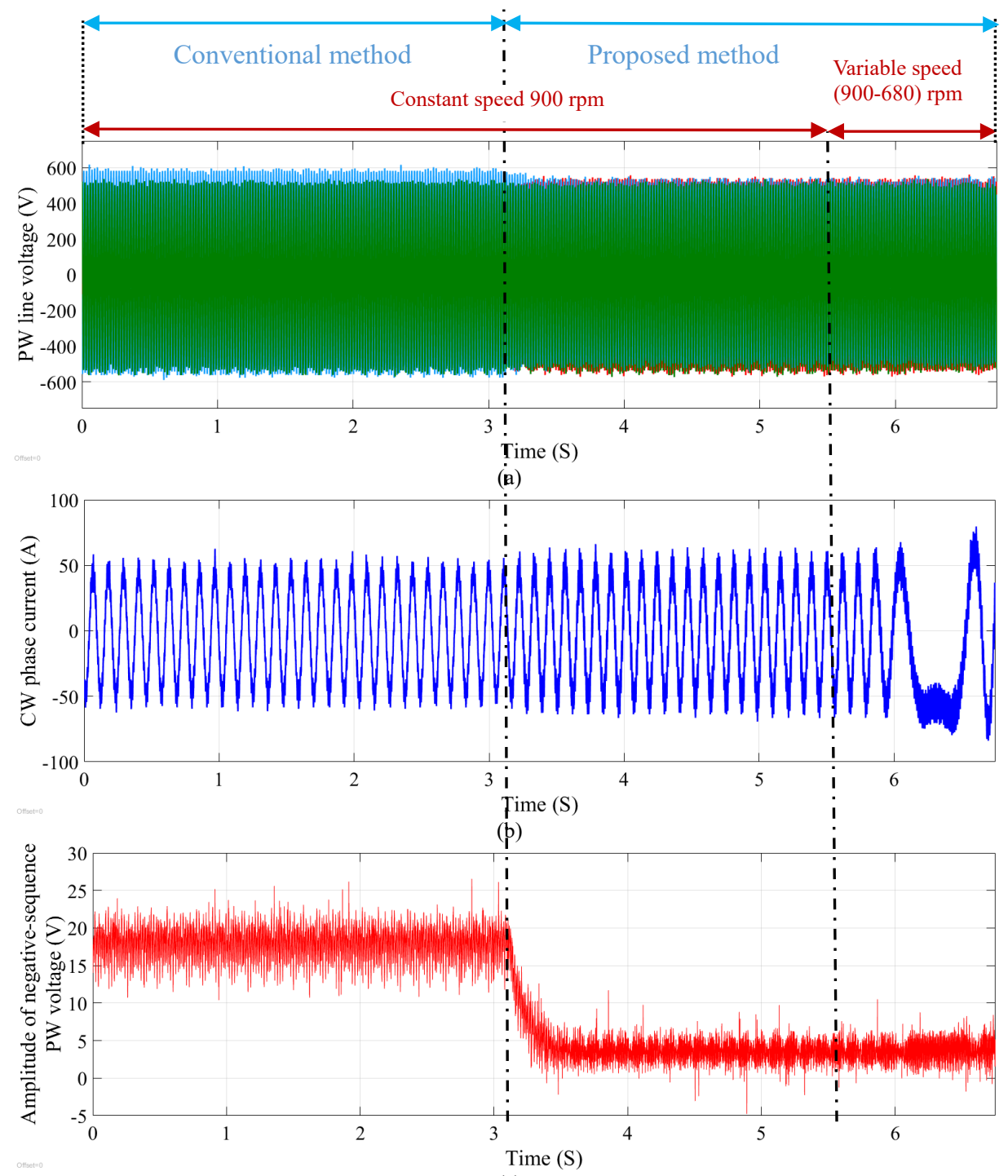

(c)

Fig. 12. Experimental dynamic performance of the proposed method with three-phase unbalanced load: (a) PW line voltage, (b) CW phase current, and (c) amplitude of negative- sequence PW voltage.

[13] Y. Liu, W. Ai, B. Chen, and K. Chen, "Control design of the brushless doubly-fed machines for stand-alone VSCF ship shaft generator systems," J. of Power Electron., vol. 16, no. 1, pp. 259-267, Jan. 2016.

[14] L. Sun, Y. Chen, L. Peng, and Y. Kang, "Numerical-based frequency domain controller design for stand-alone brushless doubly fed induction generator power system," IET Power Electron., vol. 10, no. 5, pp. 588598, Feb. 2017.

[15] X. Wang, H. Lin, and Z. Wang, "Transient control of the reactive current for the line-side converter of the brushless doubly-fed induction generator in stand-alone operation," IEEE Trans. Power Electron., vol. 32, no. 10, pp. 8193-8203, Oct. 2017.

[16]Y. Liu, W. Xu, J. Zhu, and F. Blaabjerg, "Sensorless control of standalone brushless doubly-fed induction generator feeding unbalanced loads in ship shaft power generation system," IEEE Trans. Ind. Electron., vol. 66, no. 1, pp. 739-749, Jan. 2019.

[17] W. Xu, D. Dong, Y. Liu, K. Yu, and J. Gao, "Improved sensorless phase control of stand-alone brushless doubly-fed machine under unbalanced loads for ship shaft power generation," IEEE Trans. Energy Convers., vol. 33, no. 4, pp. 2229-2239, Dec. 2018.
[18] R. A. McMahon, P. C. Roberts, X. Wang, and P. J. Tavner, "Performance of BDFM as generator and motor," IEE Proc. Electr. Power Appl., vol. 153, no. 2, pp. 289-299, Mar. 2006.

[19] X. Wei, M. Cheng, W. Wang, P. Han, and R. Luo, "Direct voltage control of dual-stator brushless doubly fed induction generator for stand-alone wind energy conversion systems," IEEE Trans. Magn., vol. 52, no. 7, pp. 1-4, Jul. 2016.

[20] P. Rodriguez, A. Luna, I. Candela, R. Mujal, R. Teodorescu, and F. Blaabjerg, "Multiresonant frequency-locked loop for grid synchronization of power converters under distorted grid conditions," IEEE Trans. Ind. Electron., vol. 58, no. 1, pp. 127-138, Jan 2011.

[21] G. Ellis, Control System Design Guide, 3rd ed. USA: Elsevier Academic Press, 2006.

[22] S. Golestan, M. Monfared, and F. D. Freijedo, "Design-oriented study of advanced synchronous reference frame phase-locked loops," IEEE Trans. Power Electron., vol. 28, no. 2, pp. 765-778, Feb. 2013. 


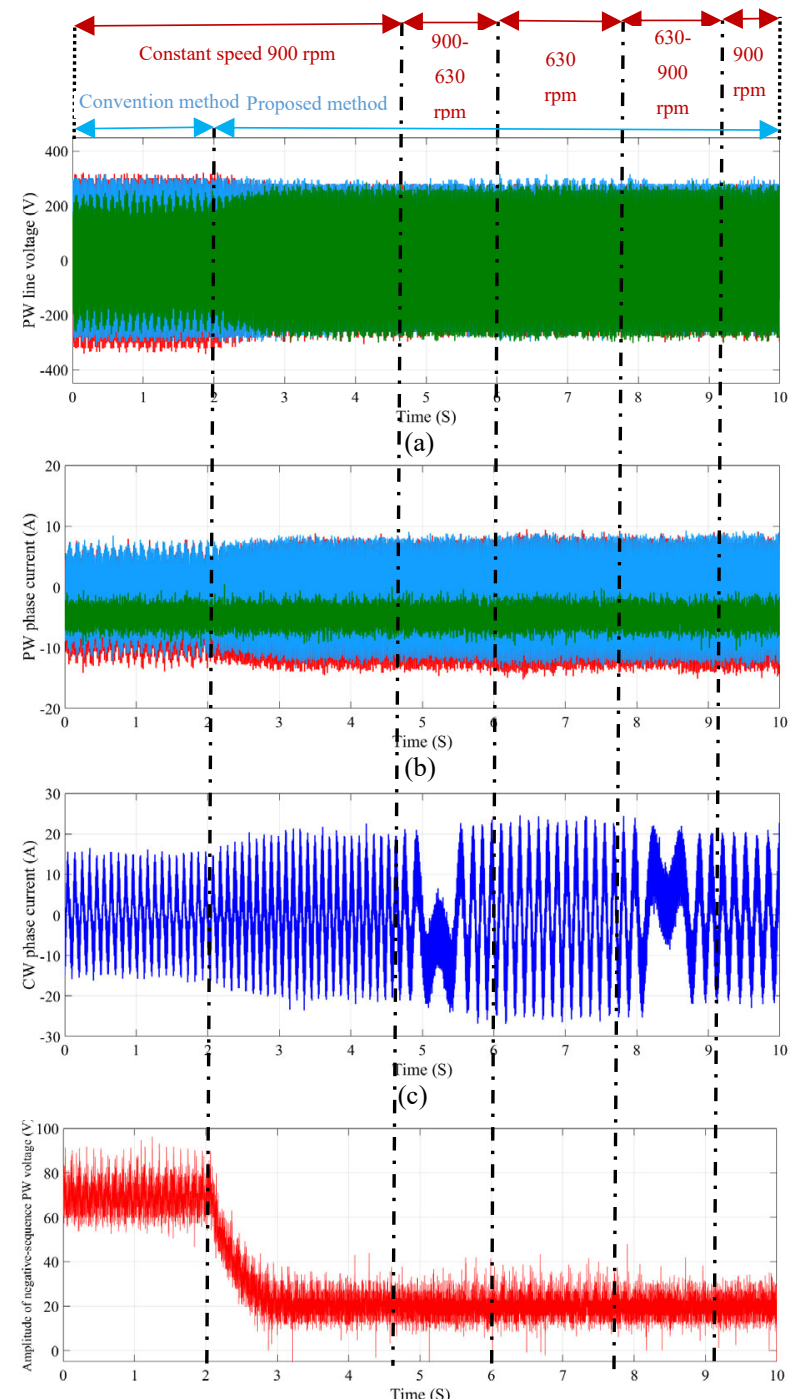

(d)

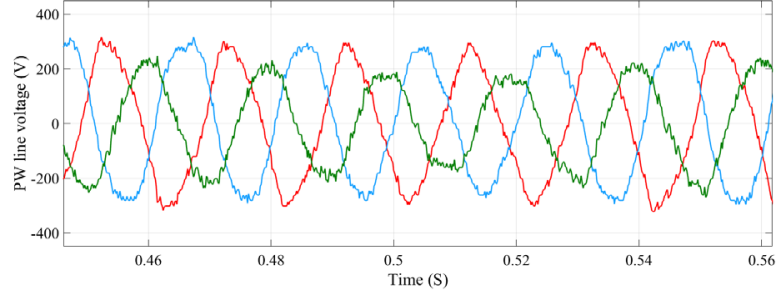

(e)

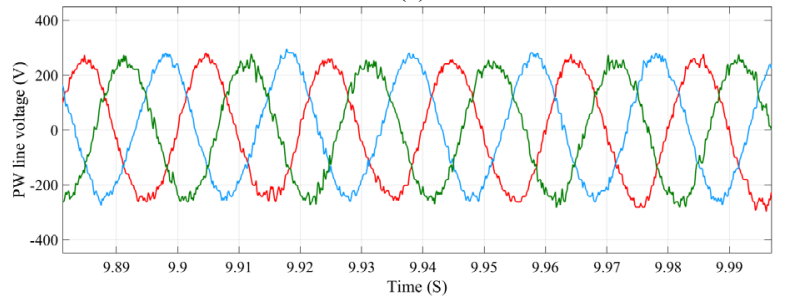

(f)

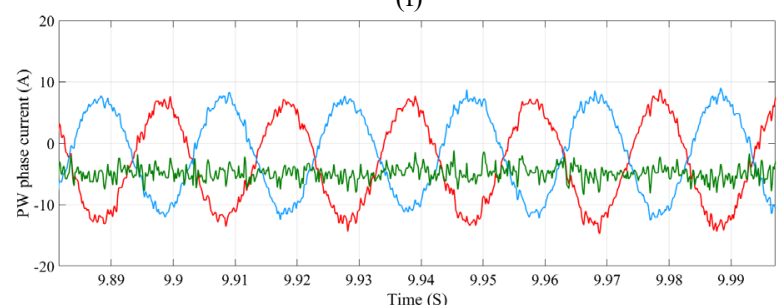

(g)

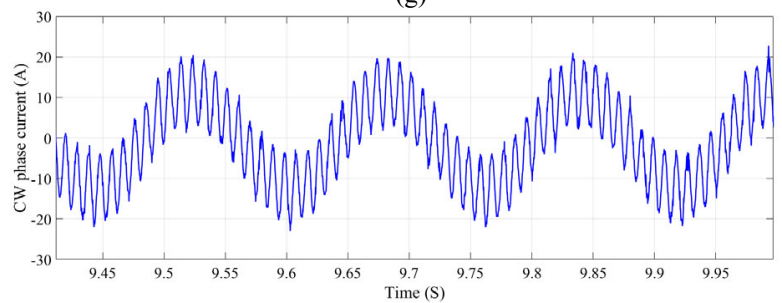

(h)

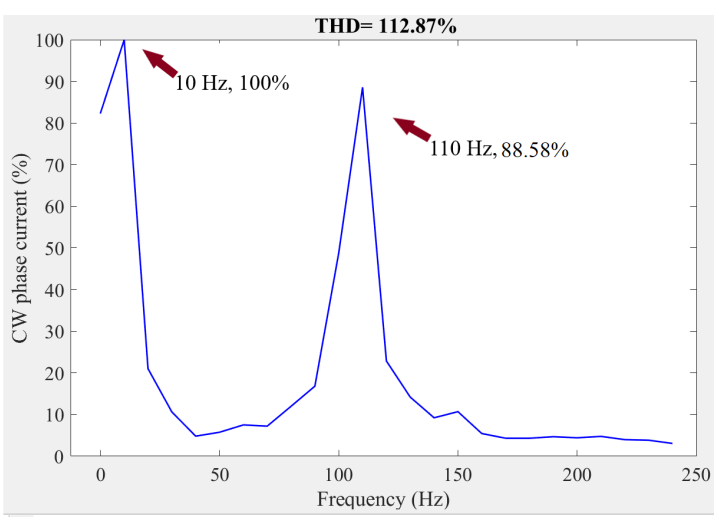

(i)

Fig. 13. Experimental results with single phase load: (a) PW line voltage, (b) PW phase current, (c) CW phase current, (d) amplitude of negative-sequence PW voltage, (e) extended scenery of (a), (f) extended scenery of (a), (g) extended scenery of (b), (h) extended scenery of (c), and (i) THD and harmonic spectrum of the CW current shown in (h). 


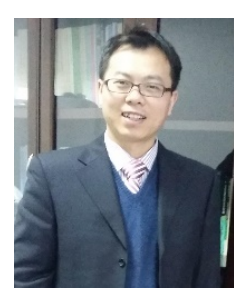

Wei Xu (M'09-SM'13) received the double B.E. and M.E. degrees from Tianjin University, Tianjin, China, in 2002 and 2005, and the Ph.D. from the Institute of Electrical Engineering, Chinese Academy of Sciences, in 2008, respectively, all in electrical engineering. From 2008 to 2012, he held several academic positions in both Australian and Japanese universities and companies. Since 2013, he has been full professor with the State Key Laboratory of Advanced Electromagnetic Engineering and Technology, Huazhong University of Science and Technology, China. His research topics mainly cover design and control of linear/rotary machines. He is Fellow of the Institute of Engineering and Technology (IET). He has served as Associate Editor for several Journals, such as IEEE Transactions on Industrial Electronics, IEEE Journal of Emerging and Selected Topics in Power Electronics, IEEE Transactions on Vehicular Technology, etc.

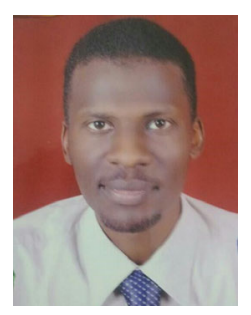

Omer Mohammed Elbabo Mohammed received the B.Sc. degree from University of Kordofan, EL-Obied, Sudan, in 2010; and the M.Sc. degree from Sudan University of Science and Technology, Khartoum, Sudan, in 2013, all in electrical engineering.

He was appointed a Lecturer in the Department of Electrical Engineering, Faculty of Engineering, University of Sinnar, Sinnar, Sudan, in 2013.

From Sept. 2016, he has been pursuing the Ph.D. degree at the State Key Laboratory of Advanced Electromagnetic Engineering and Technology, School of Electrical and Electronic Engineering, Huazhong University of Science and Technology, Wuhan, China.

His current research interests include AC electrical machine control and power quality issues.

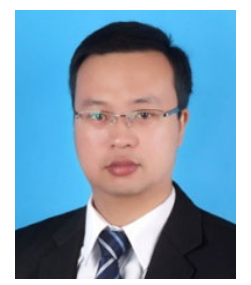

Yi Liu (M'14) received his B.E. and M.E. degrees in Automation and Control Engineering from the Wuhan University of Science and Technology, Wuhan, China, in 2004 and 2007, respectively; and his Ph.D. degree in Mechatronic Engineering from the Huazhong University of Science and Technology, Wuhan, China, in 2016.

From 2007 to 2011, he was a Lecturer at the City College, Wuhan University of Science and Technology, Wuhan, China. From March 2016 to June 2016, he was a Senior R\&D Engineer at the Fourth Academy of China Aerospace Science and Industry Group, Wuhan, China. In July 2016, he became a Postdoctoral Research Fellow at the State Key Laboratory of Advanced Electromagnetic Engineering and Technology, School of Electrical and Electronic Engineering, Huazhong University of Science and Technology.

His current research interests include AC electrical machine control and inverter systems.

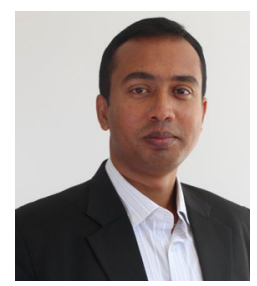

Md. Rabiul Islam (M'14-SM'16) received the B.Sc and M.Sc. degree from Rajshahi University of Engineering and Technology (RUET), Rajshahi, Bangladesh, in 2003 and 2009, respectively; and the Ph.D. degree from University of Technology Sydney (UTS), Sydney, Australia, in 2014, all in electrical engineering.

He was appointed a lecturer at RUET in 2005 and promoted to full professor in 2017. In early 2018, he joined at the School of Electrical, Computer, and Telecommunications Engineering (SECTE), University of Wollongong (UOW), Wollongong, Australia. He is also a member of Australian Power Quality and Reliability Center of UOW. From 2013 to 2014, he was a Research Associate with UTS. His research interests are in the fields of power electronic converters, renewable energy technologies, power quality, electrical machines, and smart grid. He has served as a Guest Editor for IEEE Transactions on Energy Conversion and IEEE Transactions on Applied Superconductivity. Currently he is editing a special issue for IET Electric Power Applications. 